\title{
Challenges and Difficulties facing Islamic Financial Inclusion in Women's Economic Empowerment in Yemen: Qualitative Approach
}

Lina Mohammed Abdo Alaghbari*

International Islamic University,

IIUM Institute of Islamic Banking and Finance,

Malaysia.

Email: lina.alaghbari@live.iium.edu.my

*Corresponding Author

\author{
Anwar Hasan Abdullah Othman \\ International Islamic University, \\ IIUM Institute of Islamic Banking and Finance, \\ Malaysia. \\ Email: anwarhasan@iium.edu.my

\section{Azman Bin Mohd. Noor} \\ International Islamic University, \\ IIUM Institute of Islamic Banking and Finance, \\ Malaysia. \\ Email: azmann@iium.edu.my
}

Received July, 2021; Accepted September, 2021

\begin{abstract}
The study aimed to explore the challenges and difficulties faced by Islamic financial inclusion through Islamic financial institutions (banks, microfinance, insurance) in women's economic empowerment in Yemen. This will lead to enhance women's place in economic development when finding appropriate solutions to these challenges. This study applied the qualitative approach by conducting indepth interviews with the experts comprising eighteen respondents in Islamic financial institutions. The result of respondents showed that there are a number of challenges and difficulties associated with the environment that have implications for overall institutional action and directly or indirectly contribute to women's economic empowerment. Where customs and traditions constitute the biggest external challenge facing Islamic financial institutions, as well as women's financial illiteracy, and the unstable political conditions that Yemen is going through. In addition to internal topics associated with the policies of those institutions themselves, they are ultimately subject to the impact of external problems and challenges. Furthermore, the results of the study will help decision-makers to activate the role of compulsory in society and implement effective plans and strategies to empower women economically.
\end{abstract}

Keywords: Islamic Financial Inclusion, Women, Economic Empowerment, challenges and difficulties, Yemen.

Type: Research paper

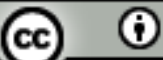

DOI: 10.51325/ijbeg.v4i3.80

\footnotetext{
التحديات والصعوبات التي تواجه الشمول المالي الإسلامي في تمكين المرأة اقتصاديَّا في اليمن: دراسة نوعية ملخص البحث :

هدفت الدراسة إلى استكثاف التحديات والصعوبات التي تواجهه الثمول المالي الإسلامي IFI من خلال المؤسسات المالية الإسلامية (المصارف، التمويل الأصغر ، التأمين) في تمكين المرأة اقتصاديًا في اليمن. تساعد الدراسة في تعزيز مكانة المرأة في التنمية الاقتصادية

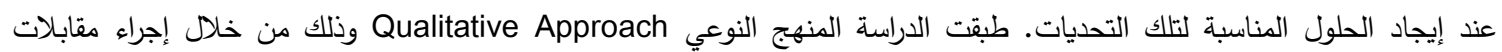




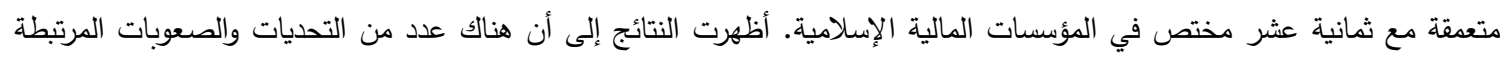

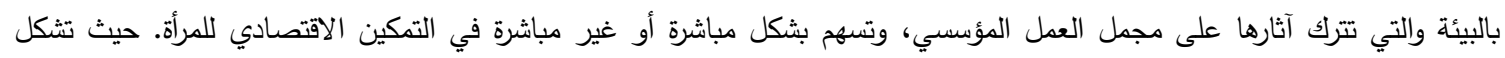

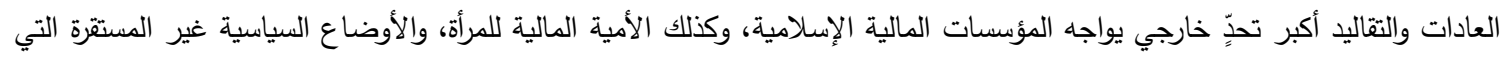

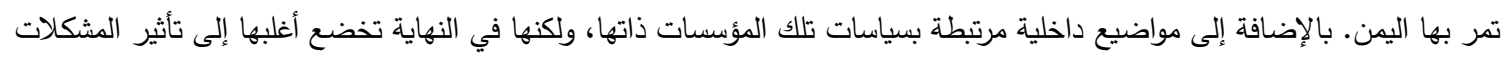

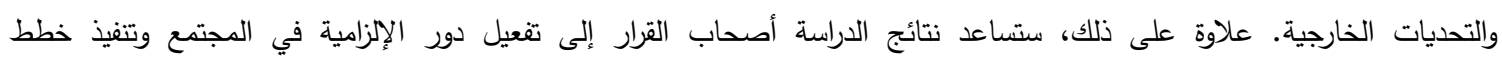
واستراتيجيات فعالة لتمكين المرأة اقتصاديًا. الكلمات الدالة: الثمول المالي الإسلامي، تمكين المرأة اقتصاديًا، التحديات والصعوبات، اليمن.

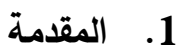

يعد تمكين المرأة اقتصاديًّا من أكثر الوسائل فاعلية للنهوض بدور المرأة في المجتمع (UNHLP (2016) وامر حاسما في أهداف التتمية المستدامة (United Nations, 2018) (SDs)، ويعتبر من القضايا المهمة التي لئي

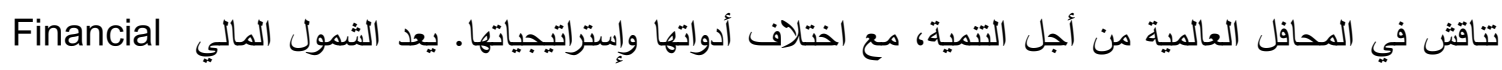

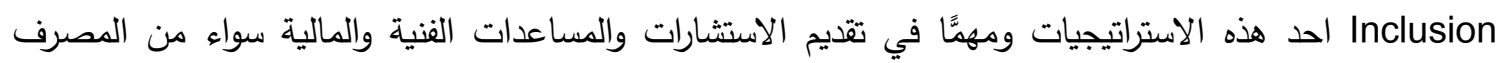

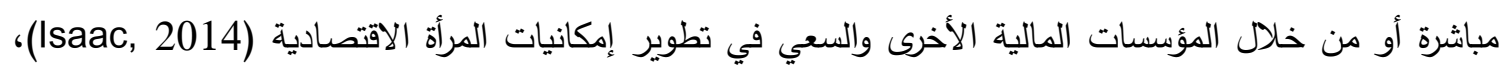
وشمول وتعزيز فرص وصولها للخدمات المالية والتمويل (صندوق النقد العربي، 2018). إلا ان المؤسسات المالية تعاني تحديات وصعوبات في شمول المرأة ماليا (مجموعة البنك الدولي، 2018). كانخفاض مستوى وجود فرون فروع لها، وارتفاع تكلفة المعاملات، وتصميم منتجات ملائمة وغيرها (Subramanian, 2014)، وللمخاوف الدينية دوراً

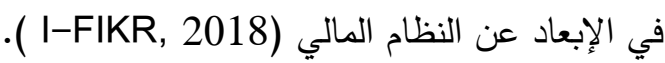

يحقق التمويل الإسلامي قيمة مضافة إلى قضية الثمول المالي من عده طرق أهمها استخدام عقود مشاركة وتقاسم المخاطر، وبديلا للأفراد الذين أحجموا عن استخدام الخدمات المالية التقليدية الرسمية القائمة على الربا لأسباب

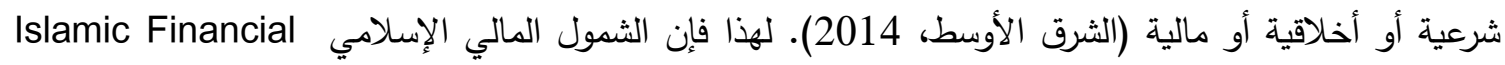

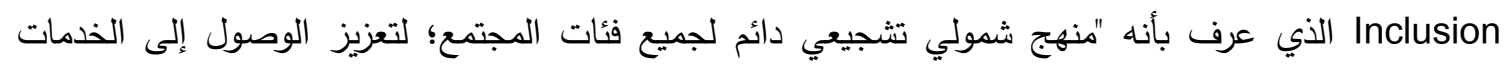
والمنتجات المالية الإسلامية البعيدة عن الربا واستخدامها بجودة عالية وتكلفة مناسبة، والسعي إلى شمول الفئات المستبعدة من النظام التقليدي؛ لأسباب دينية وغيرها، وتعزيز الوصول إلى خدمات التمويل الاجتماعي الإسلامي وإني Islamic social finance

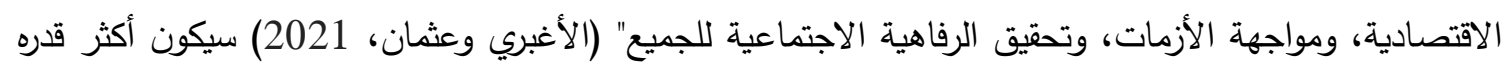

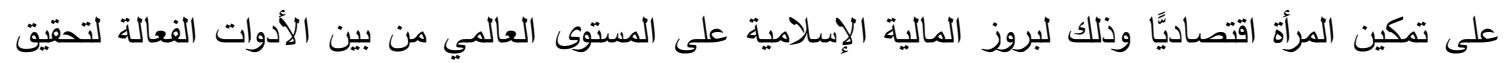

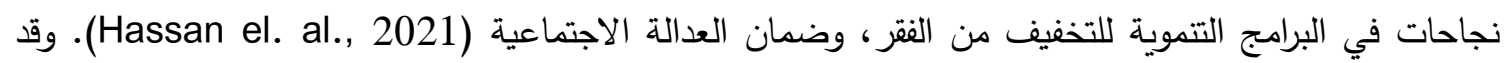
يصبح هدفًا وطنيَّا مهمًّا في اليمن لتعزيز تمكين المرأة اقتصاديًا، وذلك لأهمية الصناعة المالية الإسلامية في اليمن

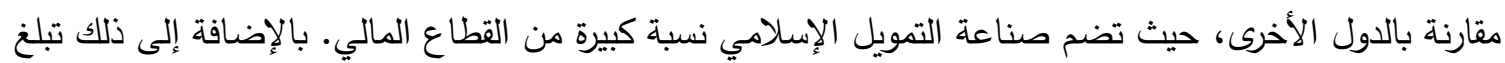
حصة المصارف الإسلامية من إجمالي أصول المصارف في اليمن 51.5٪، وتعد النظم الرقابية والتنظيمية متميزة عن نظم المصارف التقليدية (Demirguc-Kunt, et al.,2013).

يثهد اليمن إقصاء واضحًا للمرأة من الناحية الاجتماعية والسياسية والاقتصادية، لهذا أدركت اليمن الضرورات

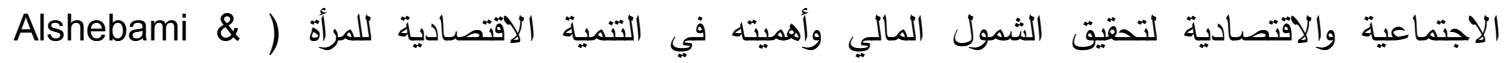

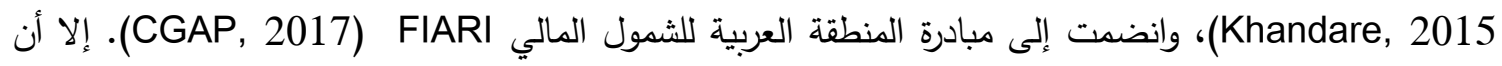


الوصول إلى النظام المالي الرسمي لم يصل بعد إلى جميع سكان اليمن ولا سيما النساء، .2\% فقط من النساء

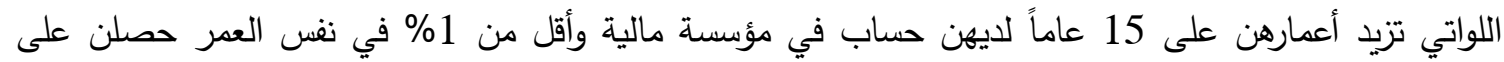
قرض من مؤسسة مالية (The Global Findex Database, 2017). و89\% من النساء اليمنيات غير قادرات على الحصول على قرض مصرفي بمفردهن (البنك الدولي، 2014)، وهذا يحد من فرص قيام النساء وبالذات ذوات الاخل المنخفض بأي نثاط تجاري قد يشارك في تتميـة الأسـرة (Alshebami \& Khandare, 2014;2015). ويحد من مشاركة المرأة في العملية السياسية حيث يعد الوضع الاقتصادي القوي للمرأة شرطًا مهمَّا لذلك فئك .(Muhammad et al., 2019)

مما سبق يظهر جوهر مشكلة الدارسة في ظل عدم قدرة النساء اليمنيات على الوصول واستخدام الخدمات المالية بسهولة ويسر وتخلفهن عن الرجال في ذلك، وهذا يؤكده الفارق الكبير بين الذكور والإناث في ملكية الحسابات 11\% للذكور و2\% للإناث (The Global Findex Database, 2017). لهذا يثار تساؤل في هذه الدراسة عن تلك التحديات والصعوبات التي تحجم الثمول المالي الإسلامي من خلال مؤسساته (مصارف، التمويل الأصغر، التأمين) في تمكين المرأة اقتصاديًا في اليمن، وتقوض قدرات تلك المؤسسات في إيصال خدماتها الى

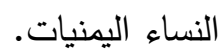

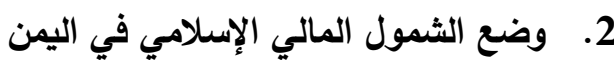

ظهرت فكرة إنشاء المصارف الإسلامية في اليمن منذ بداية تأسيس المصارف الإسلامية في العالم الإسلامي، حيث

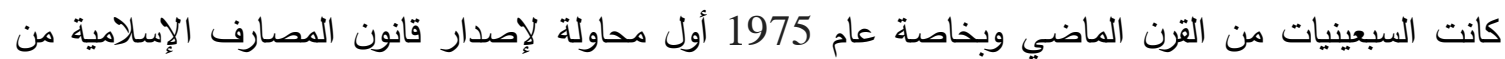
مجلس الثعب، لكن الدحاولة واجهتها الظروف والمتغيرات التي أعاقت خروج القانون إلى حيز الوجود (البشيري،

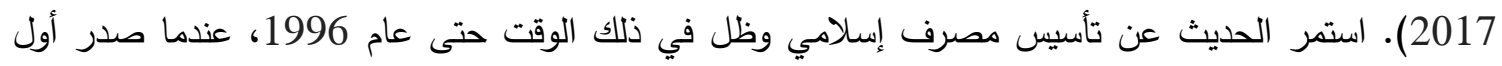
قانون يمني لإنشاء المصارف الإسلامية. في نفس العام، تم إنشاء أول مصرف إسلامي في اليمن هو المصرف

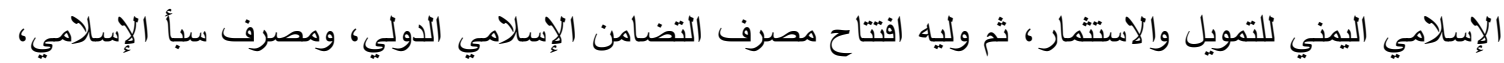
ثم مصرف اليمن البحرين الثامل في 2002، ويرجع ذلك إلى أسباب سياسية، بما في ذلك التغيير في النظام

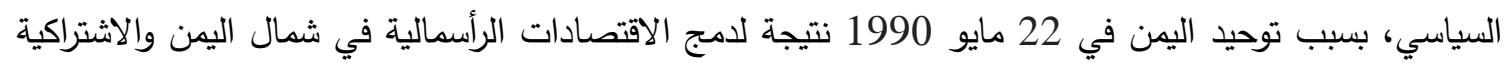
في جنوب اليمن. ومع ذلك، بسبب السيطرة الكبيرة على السوق المصرفي من المصارف التجارية ولا سيما الحكومة، لهال

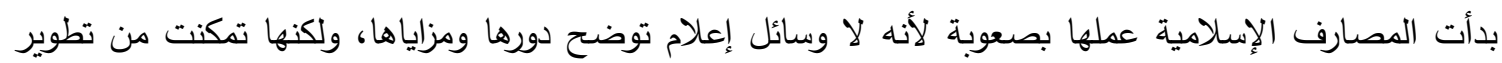
إمكاناتها من حيث حجم أو النشاط أو عدد الفروع حتى إفلاس أول مصرف تجاري يمني المصرف لإنه الوطني للتجارة

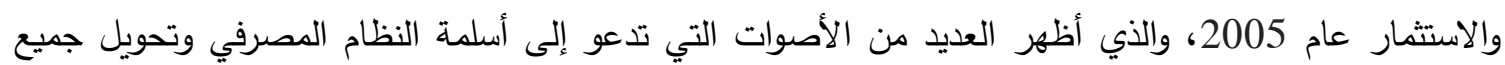

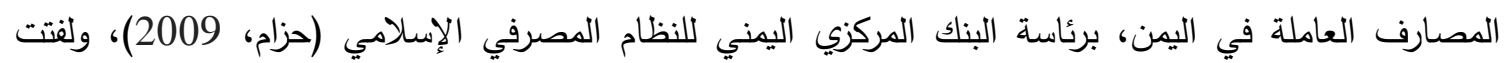

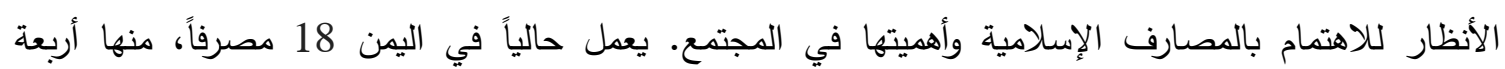
مصارف إسلامية، وثمانية مصارف تقليدية، وأربعة مصارف أجنبية، ومصرفان متخصصان في التصان التمويل الأصغر (البنك المركزي اليمني، 2019).

على الرغم من أن صناعة التمويل الأصغر في اليمن بدأت عام 1997 عن طريق الصندوق الاجتماعي للتمية، إلا أنها واجهت الكثير من العقبات بين برامج تمويل أصغر تفتح وتتهار، ومؤسسات تعمل فرادى أو تتدمج بعضها لأنها مع بعض، حتى عام 2006، قام مصرف التضامن الإسلامي الدولي - أكبر الدصارف الخاصة في اليمن بإنشاء برنامج خدمة المشاريع الصغيرة والأصغر، ويقدم من خلاله قروضًا لهذه المشاريع ومثلت هذه المبادرة أول 
مشاركة للقطاع اليمني المصرفي الخاص في الصناعة المالية للمشاريع الصغيرة والأصغر، وفي أكتوبر 2008 بدأ مصرف الأمل للتمويل الأصغر عملياته، حيث شكل منعطفاً جديداً في أحداث صناعة التمويل الأصغر في اليمن، فكان أول مصرف إسلامي متخصص في الخدمات المالية الصغيرة والأصغر ، ويعتبر القانون اليمني رقم 15 لسنة 2009م واحد من أكثر قوانين التمويل متتاهي الصغر تطوراً في منطقة الشرق الأوسط وشمال أفريقيا (شبكة اليمن

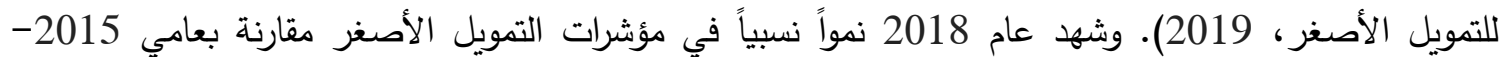
2016 (وزارة التخطيط والتعاون الدولي، 2018).

تعد اليمن من أقدم الدول العربية التي عرفت التأمين حيث يتجاوز 150 عاماً (جمعية البنوك اليمنية، 2020)، إلا أن التامين الإسلامي لم يتأسس فيها إلا منذ زمن ليس ببعيد، وذلك من خلال الرغبة الصادقة في استثمار الأموال

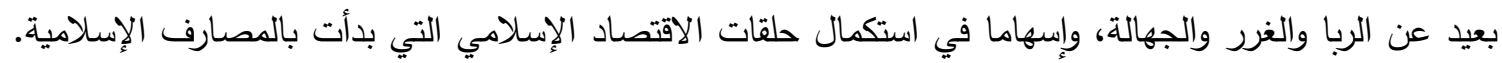

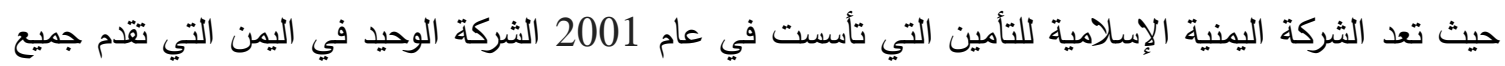

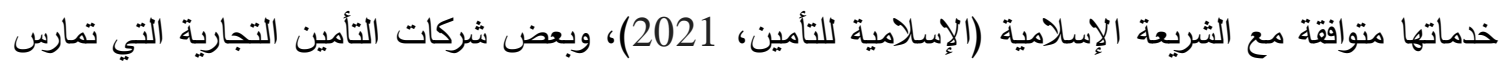
نشاطها من خلال فتح نوافذ إسلامية، مثل كاك للتأمين، والمتحدة للتأمين وغيرهم.

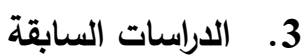
1.3

التمكين الاقتصادي للمرأة يعكس مدى تقدم المجتمع ونهضته في المجالات المختلفة، لما يعطي المرأة من حق

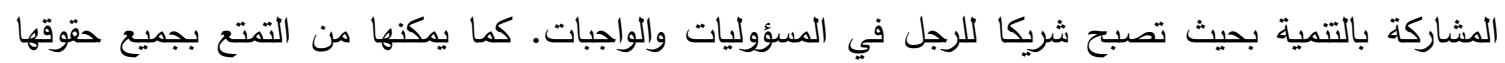
السياسية والاجتماعية والاقتصادية (Alshebami \& Khandare, 2015). وتتحقق المكاسب الاقتصادية للمرأة من خلال اندماجها في النشاط الاقتصادي وارتقاع نسبة مشاركتها في سوق العمل، وإسهامها في المشاريع سواء كان صغيرًا أم كبيرًا، مما يؤدي إلى توفير مصدر دخل دائما لها، ولا تعود عالة على المجتمع، وتتجاوز النظرة

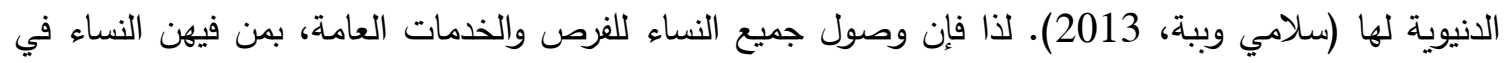

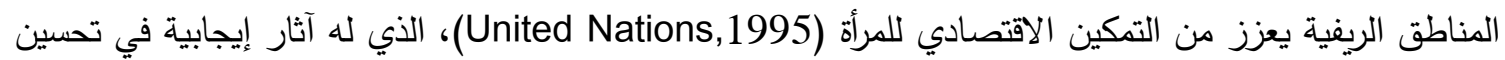

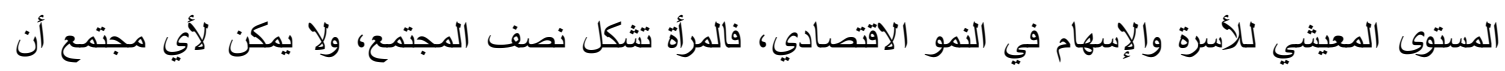
يتقدم ويتطور ونصفه الآخر عاطل أو معطل أو ضعيف. ومن دون مشاركة المرأة في مختلف المستويات سواء

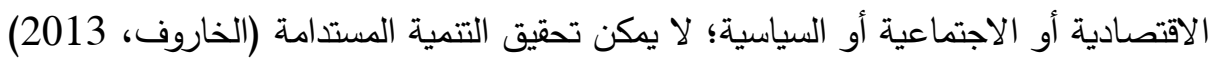

في حين أنه يمكن ملاحظة أن تعريفات تمكين المرأة قد اشتملت منذ البداية على بعد اقتصادي، حيث تبنى البنك

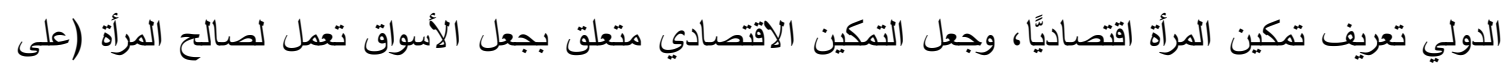

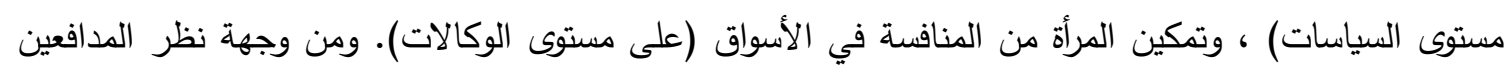

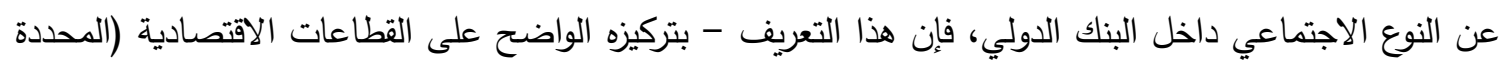

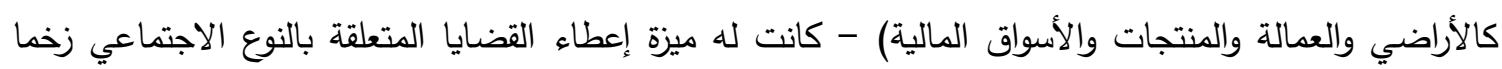
أكبر على المستوى المؤسسي (Kabeer, 2012).

2.3

تأتي الشريعة الإسلامية لتحقيق أهداف العدالة الاجتماعية من خلال وضع معايير إلهية لاقتصاد متوازن (العمر، 2003)، فتحول بذلك تمركز الأموال وسرعة نمائها لدى طبقة اجتماعية والذي يؤدى الى التفاوت الإتهن الاجتماعي 
(النبهان ، 1984). وبما أن الإسلام أكثر شمولا من خلال عملية التوازن بين الجوانب الروحية والمادية والعقلية والوجدانية، لهذا حرم الربا، فجعل فكره الوصول إلى خدمات مالية ربوية محرمة، حتى قبل تقديمها واستخدامها بجودة عالية، وأوجد الحكمة في تحريم الربا وهو الظلم الذي يقوم على زيادة الأعباء المالية على اقتراض الأموال (الساعاتي، 2012). وبما أن النظام الإسلامي والنظام الربوي متقابلان لا يلتقيان في تصور ، ولا يتفقان في أساس، ولا يتفقان في نتيجة، وكل منهما يقوم على تصوُر للحياة والأهداف والغايات يُناقض الآخر تمام المناقضة، وينتهي إلى ثمرة في حياة الناس تختلف عن ثمرة الآخر كل الاختلاف (قطب، 1995). لهذا فأن الفكرة الدينية بين الشمول المالي الإسلامي ونظيره التقليدي TFI مهمة، وذلك من خلال تعزيز وصول أفراد المجتمع إلى منتجات وخدمات مالية إسلامية

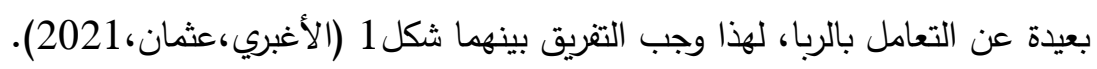

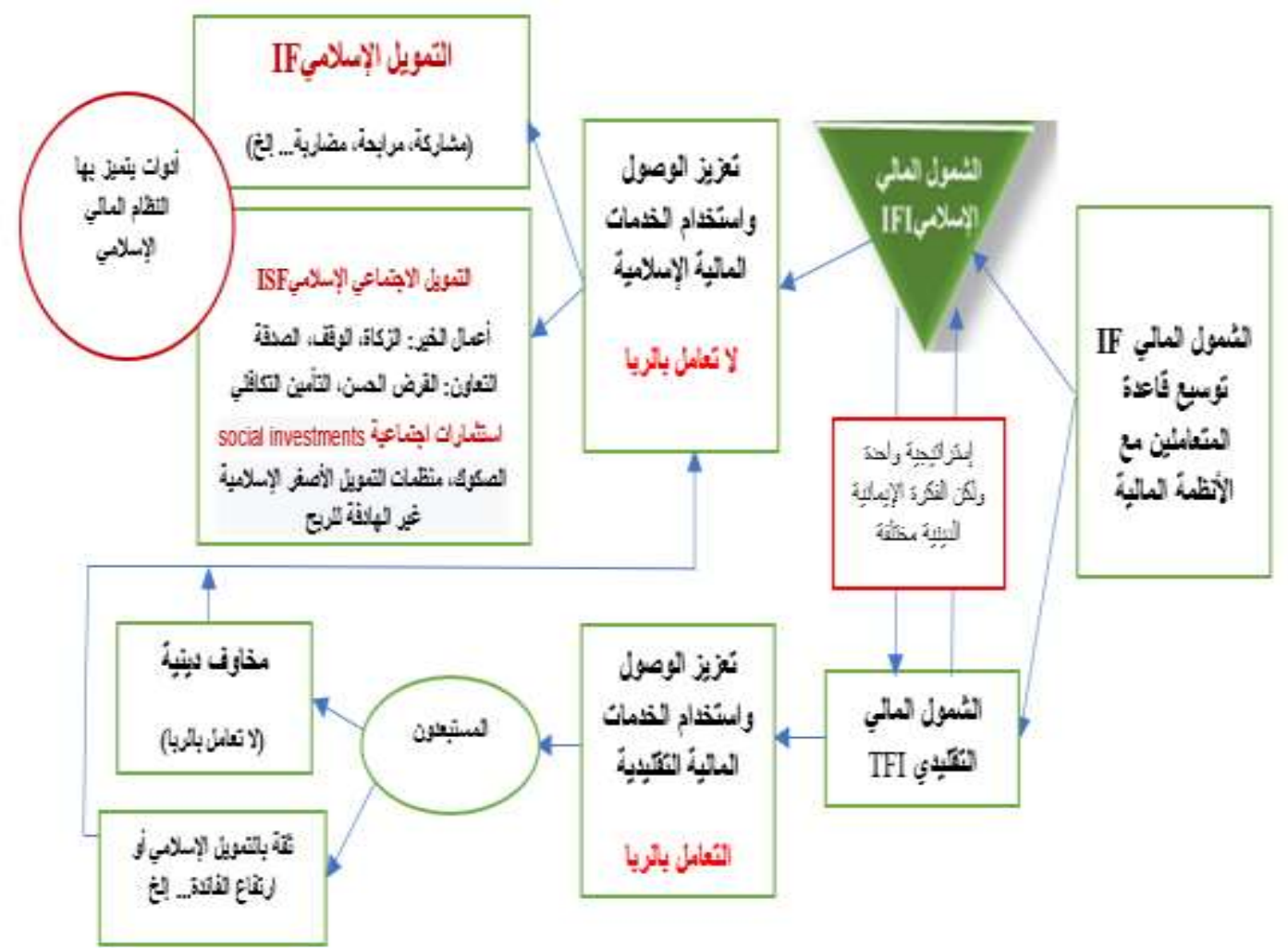

الشكل 1 الشمول المالي الإسلامي IFI و الشظيره التقليدي

المصبدر: الأغبري، عثمان، 2021

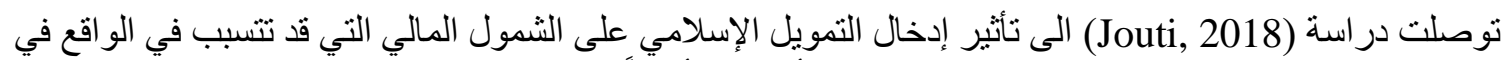

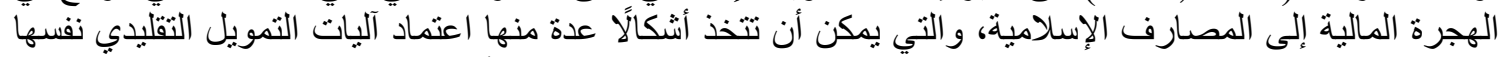

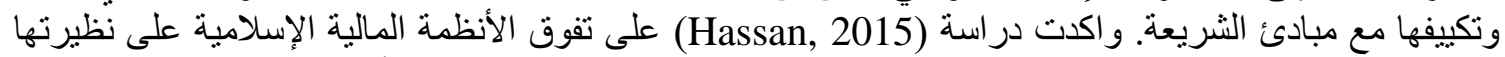

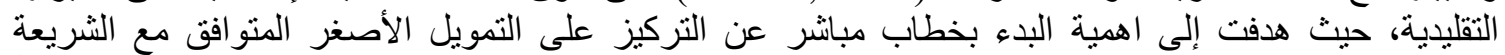

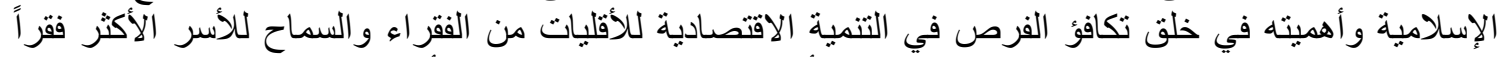

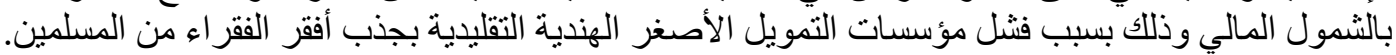

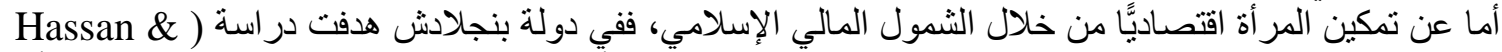
(Saleem, 2017

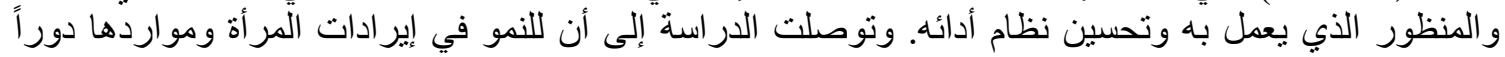


كبيراً مهمًَا في تحسين الحرية المالية للمر أة، و أنه من الضروري إعادة توجيه التمويل الأصغر الإسلامي في الإسهام

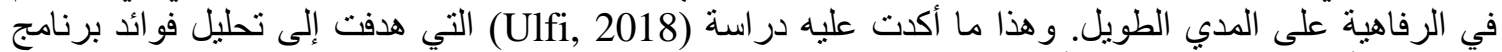

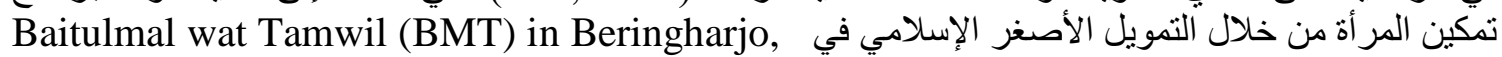
Indonesia

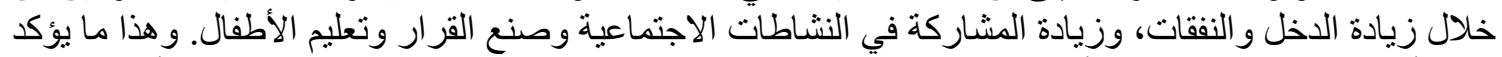
على أن مؤسسات التمويل الأصغر الإسلامية ليس فقط تستهدف النساء وحدهن بل تستهدف الأستاعل الأسرة بعامة

(Ahmed, 2002)

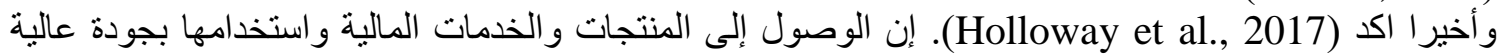

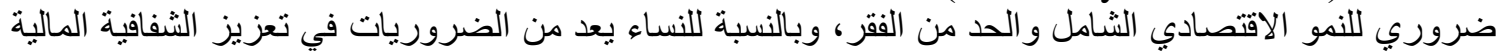

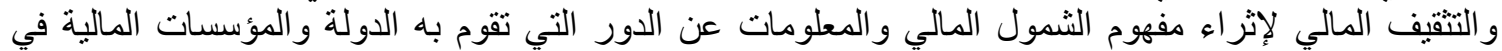

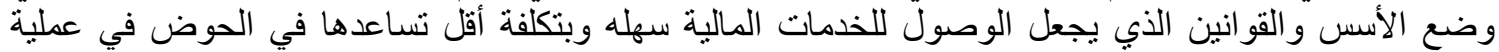
الاستثمار و التطوير الاقتصادي في أي بلد حول العالم.

تتعرض المؤسسات المالية لمعوقات في تمكين المر أة اقتصاديًّا، حيث هدفت دراسة (Ali, 2019) الى استكثاف التهاف

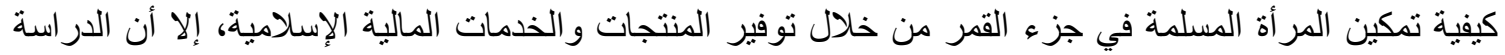
توصلت الى عو ائق تحول من ذلك منها أن النساء لا يملكن المال لاستخدام الخدمات المالية ويفتقرن إلى المعرفة

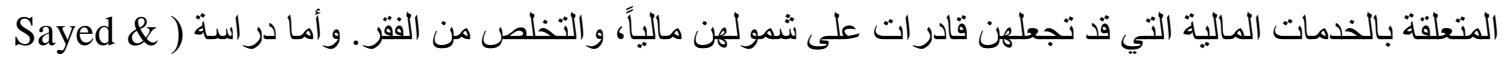

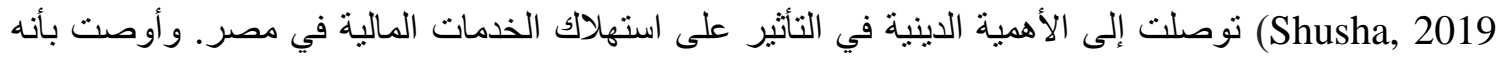
يتحتم على المؤسسات المالية مر اعاة دمج المبادئ الدينية في تصميم المنتجات والثئ والخدمات المالية في زيادة استهلاك

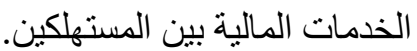

وفقاً لـــ (رمضان، 2019) أن أهم المعوقات التي يتعرض لها المصارف في تمويل مشاريع المرأة الصغيرة

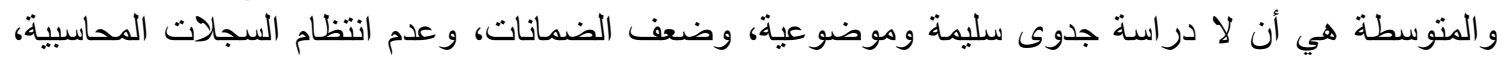

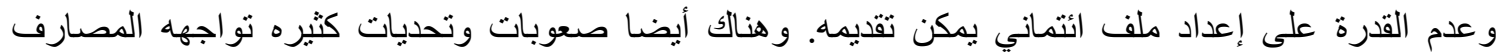

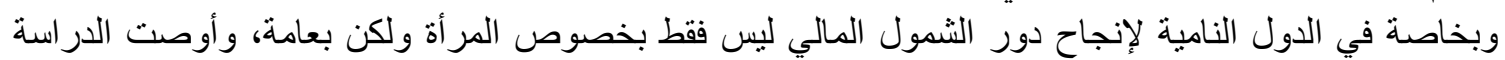

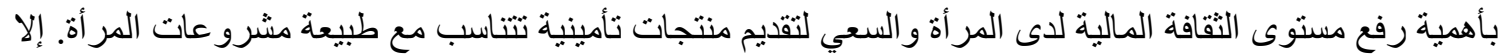

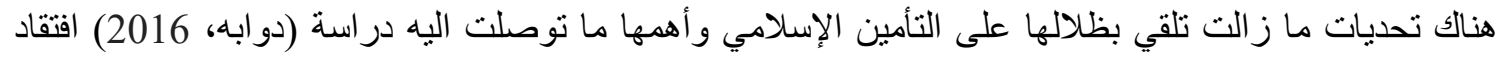

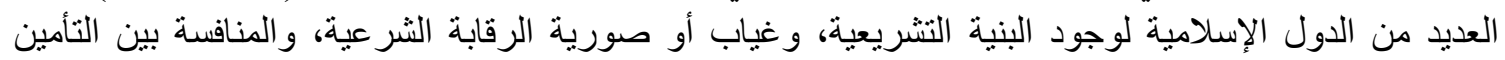

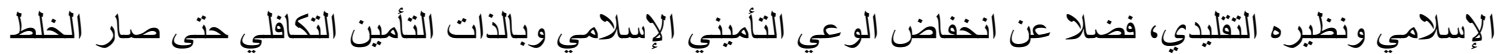

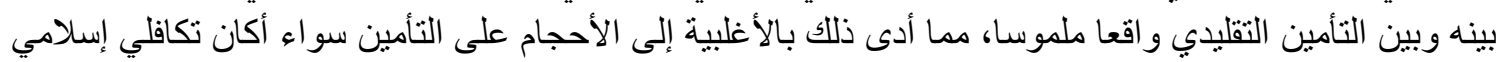
أو تقلبدي لضبابية الرؤية الثرعية، وانعدام الثقة، وسدا للذر ائع. الذي تفقده أهم أهدافه في الإسهام في عملية التنمية وتوفير البديل الثرعي للتأمين لجمهور المسلمين.

أما في السياق اليمني، حققت در اسة (Alshebami \& Khandare, 2015) في قضية تحديد التحديات التي تو اجه الهي

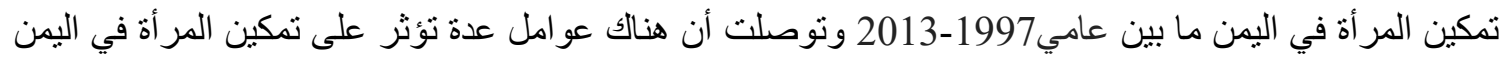

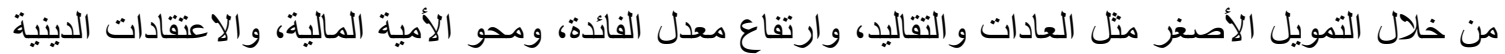

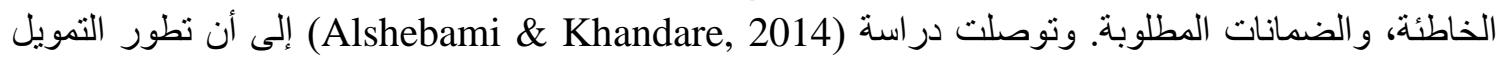

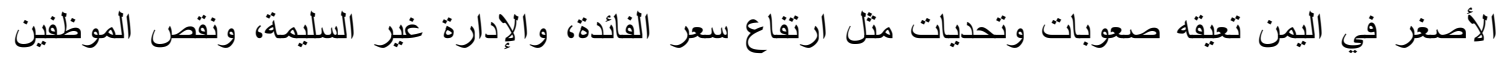

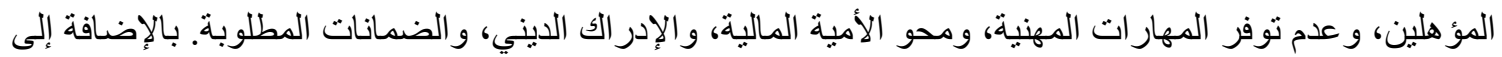

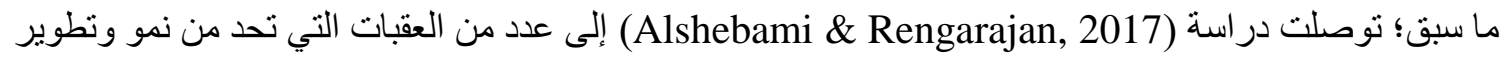

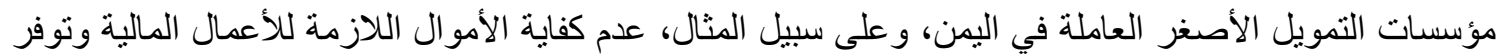

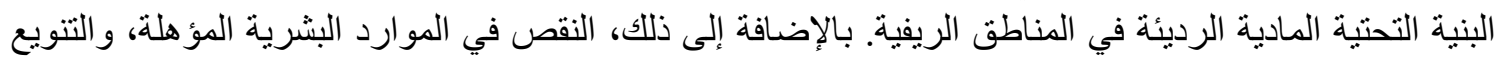

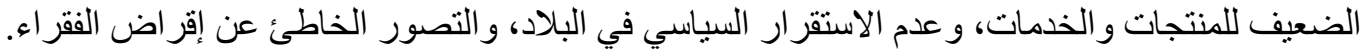


ويتبين مما سبق ذكره أن الأدبيات السابقة في السياق البمني، تطرقت الى تحديات وصعو بات ولكن اغلبها من خلال

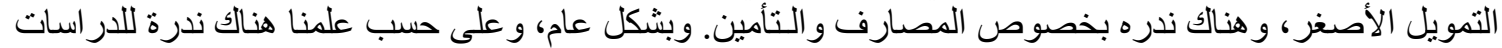

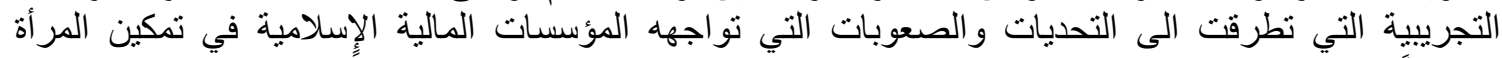

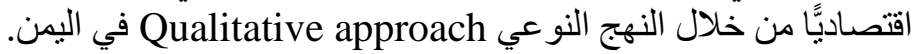

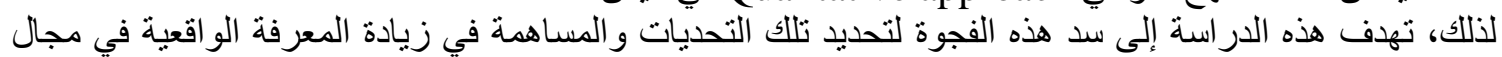

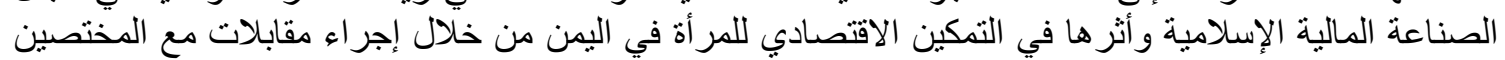

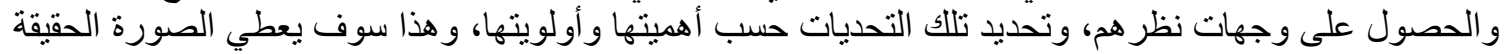
لو اقع التمكين الاقتصادي للمرات لنطر اليمنية.

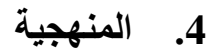

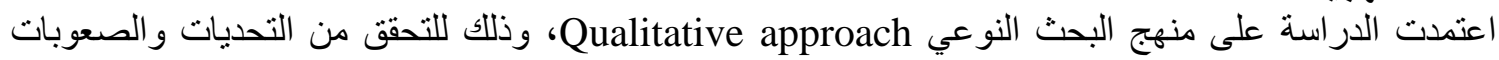
التي تو اجه الثمول المالي الإسلامي في التمكين الاقتصادي للمر أة في اليمن.

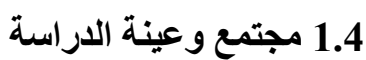

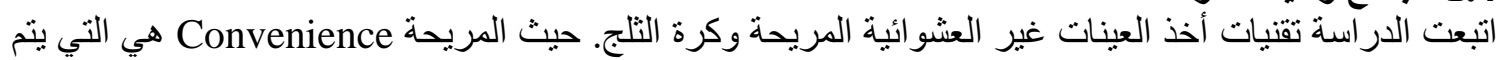

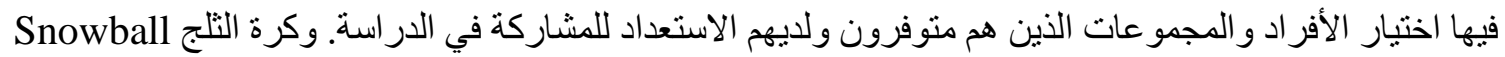

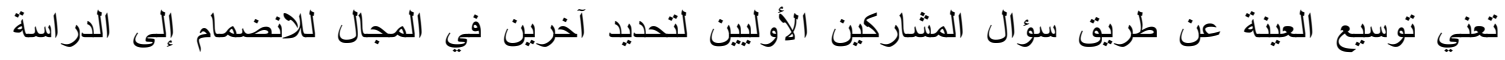

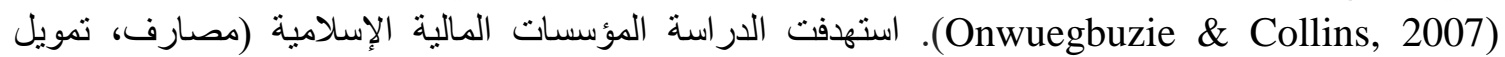

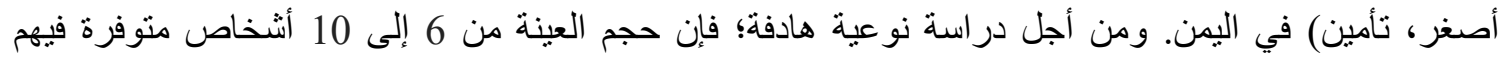

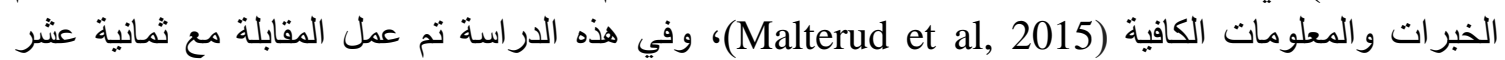

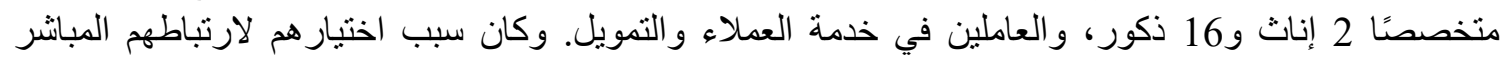

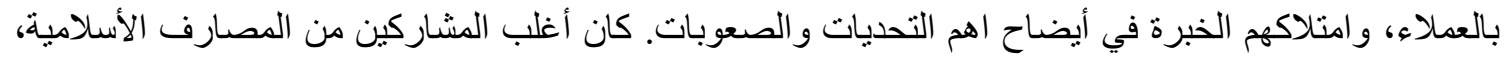

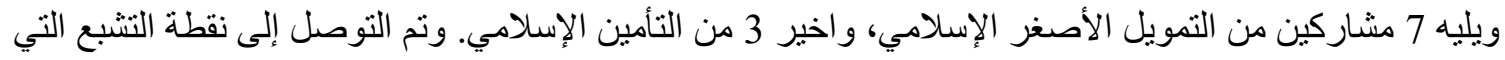
لا يتم فيها ملاحظة معلومات أو مو اضيع جديدة في البيانات (Guest.et al, 2006).

2.4

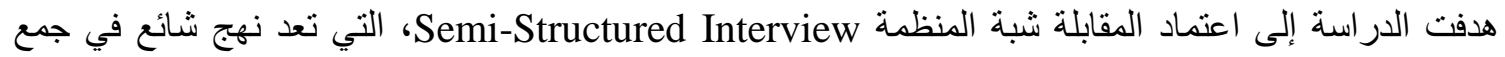

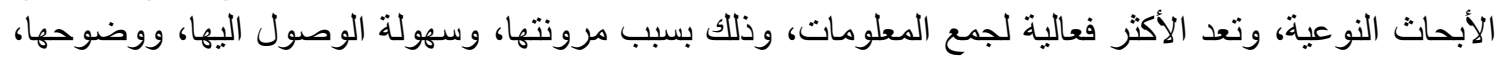

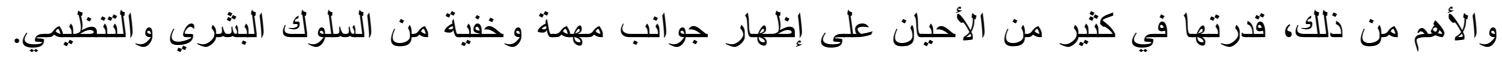

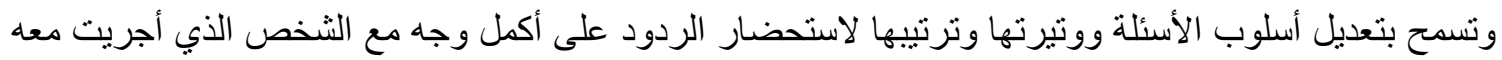

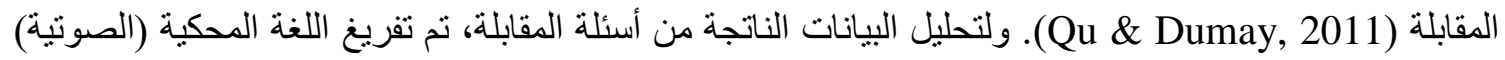

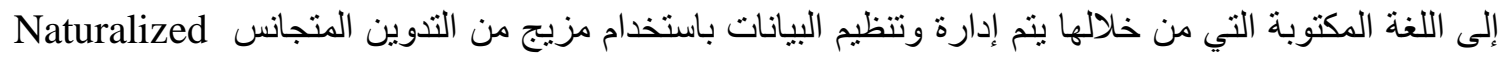
Transcription

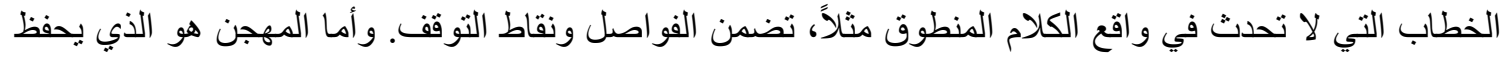
خصائص اللغة الثفهية مثل التمتمة وغير ذلك (Mero-Jaffe, 2011; Nascimento \& Steinbruch, 2019).

3.4 تحليل البيانات

استخدمت الدراسة البانات الية التحليل الموضوعي Thematic Analysis لاكتشاف المعاني الكامنة لما قيل في

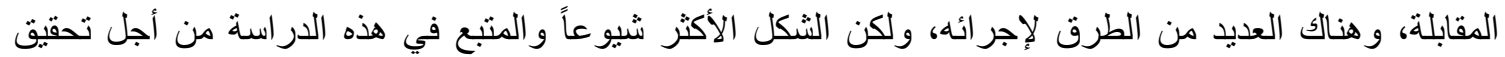

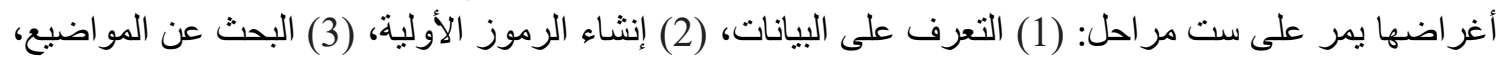

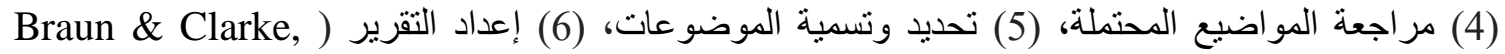

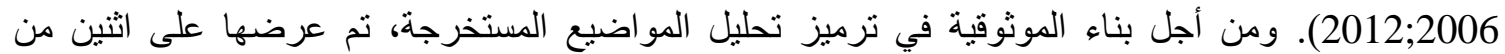

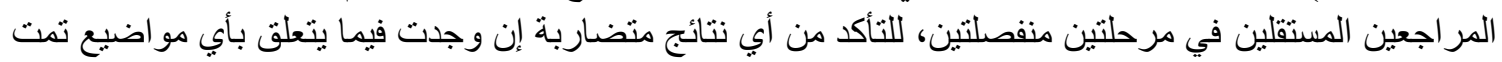

إضافتها أو أز التها (Miles \& Huberman, 1994).

أخيرا، نم تقديم المقابلات من خلال ثماني موضوعات بناءً على الردود والآراء التي أدلى بها المستجييين وتم

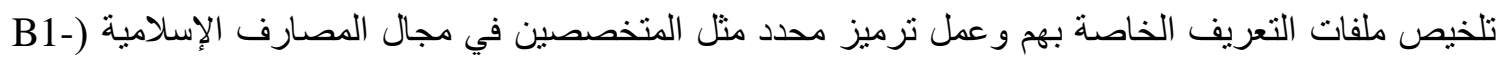


B8). أما الذين يعملون في التمويل الأصغر الإسلامي فرمزهم (M1-M7)، وأخيرا المتخصصون في مجال التأمين الإسلامي (B1-I3). (I1).

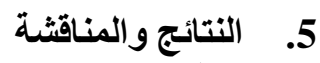
تشير غالبية وجهات نظر المستجيبين إلى أن هناك مو اضيع (تحديات وصعوبات) خارجية مرتبطة بالبيئة التي تعمل

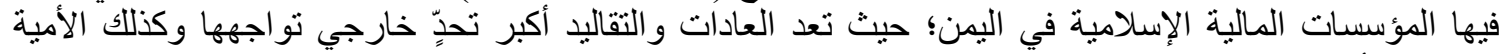

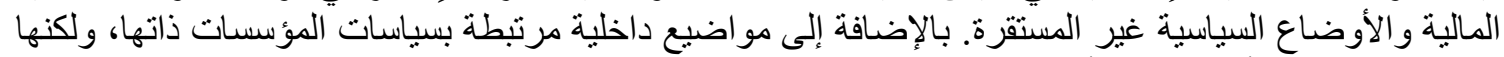

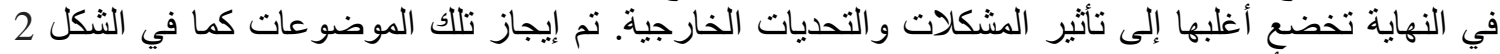
ومناقشتها حسب أهميتها لدى المستجيبين.

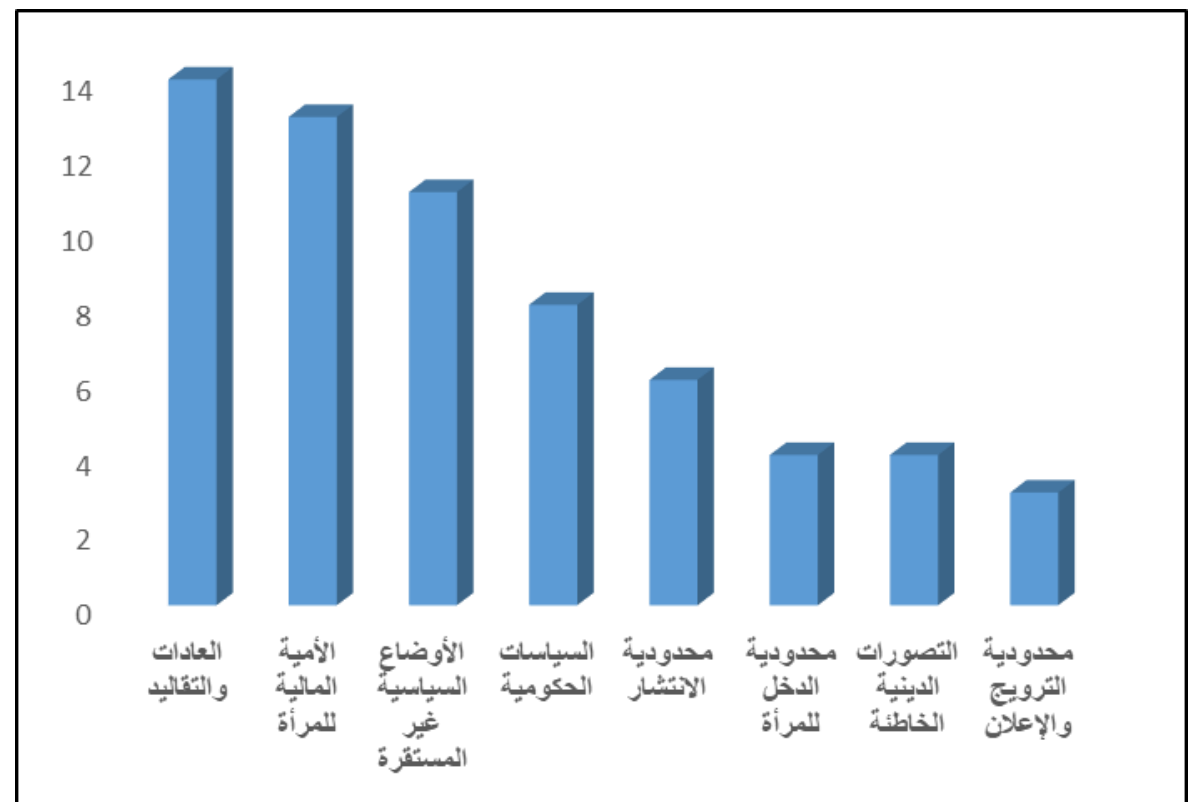

الشكل 2 التحديات والصعوبات التي تواجه الشمول المالي الإسلامي من خلال المؤسسات الإسلامية

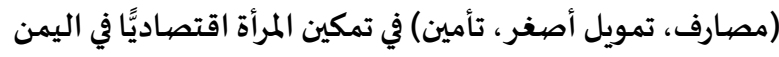

\section{الموضوع الأول Theme 1 العادات والتقاليد}

تكثف الدراسة أن العادات والتقاليد تم تحديدها من قبل أغلب المستجيبين بالتحدي الرئيس التي تواجه المؤسسات المالية الإسلامية في تمكين المرأة اقتصاديًّا في اليمن، وتم الإثارة إلى وجهات فئل نظرهم كما يأتي:

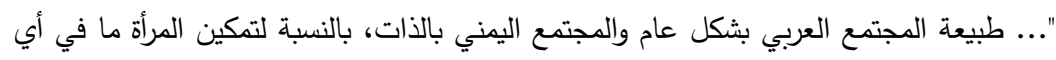

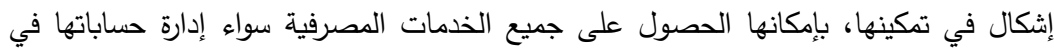

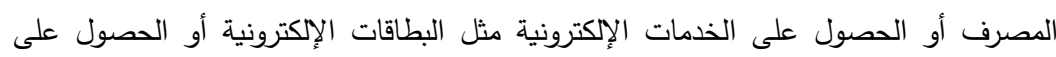

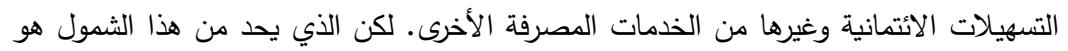

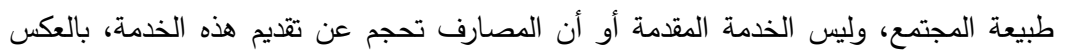

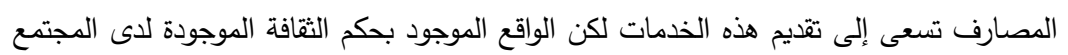

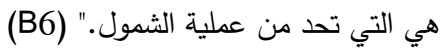


"... أكثر الصعوبات التي تواجهنا في اليمن هي العادات والتقاليد. أكثر النساء صاحبات نشاطات منزلية تكون

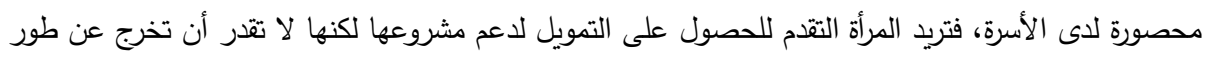

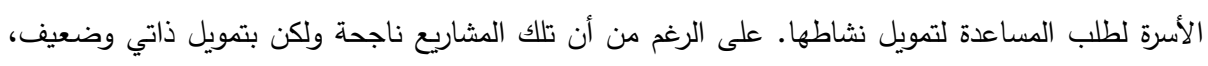

وأحيانا أي أزمة مالية يضطر المشروع إلى الأغلاق." (M2)

"... خدمات المصرف متاحة للجميع دون أي تقصير وينظر للجميع نظرة واحدة سواء كان رجل أو امرأة من

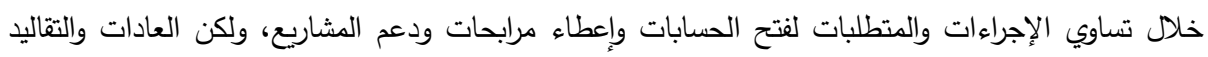

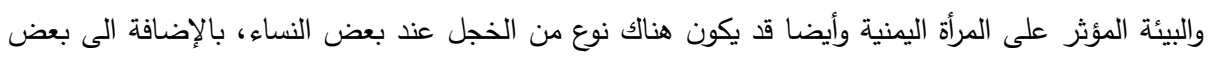

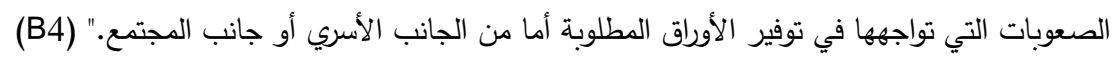

"... نحاول بقدر المستطاع الوقوف إلى جانب النساء وتثجيعهن للحصول على تمويل، وفي كثيرات تريد ذلك الكياء

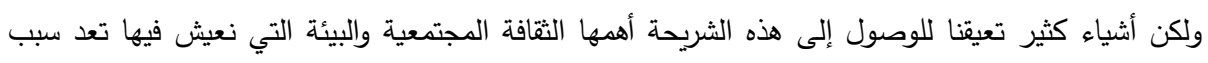

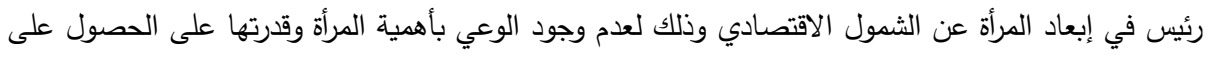

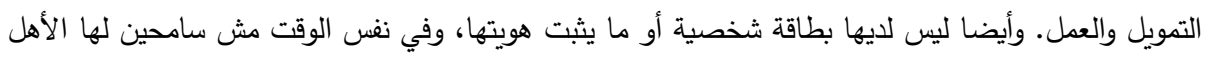

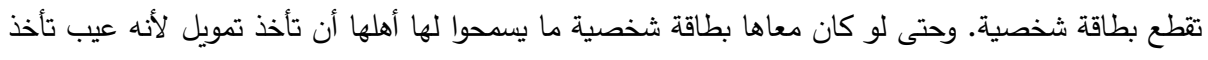

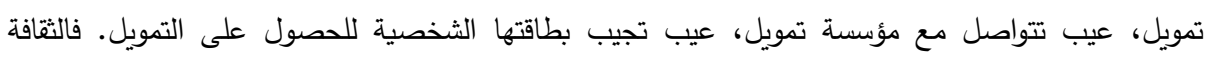

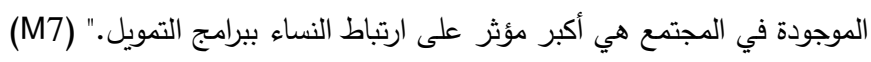

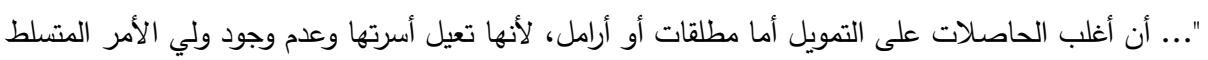

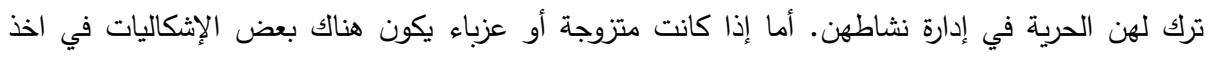

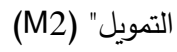

"... لازم موافقة ولي الأمر على التمويل، في حالة كانت متزوجة، بحكم المجتمع القبلي حتى لا يحدث أي

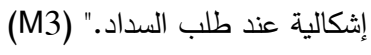

"... عندما تيجي تحدث المرأة عن أي خدمة، تقول لازم ترجع لأهلها أبوها أو زوجها تستأذن ما تقدر تعمل

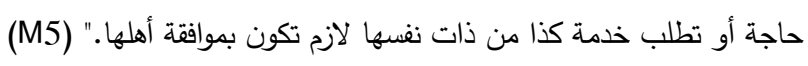

"... العادات والتقاليد مؤثرة ليست فقط في الريف وحتى في المدينة والمرأة لا تقدر تفتح مشروع إلا يكون متقبل

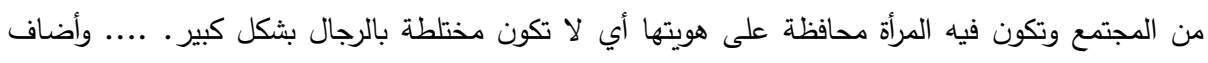

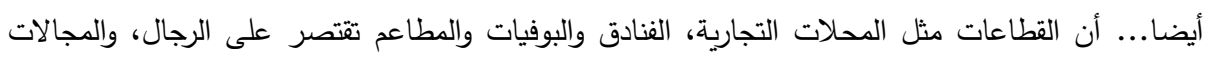

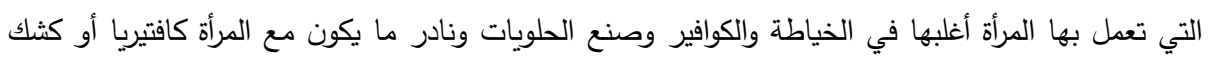

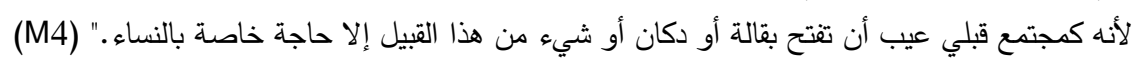

"... العادات والتقاليد هي أكثر القيود على النساء، عدم قدرة المستثرة فتح مشروع خاص بها مثل محل أو

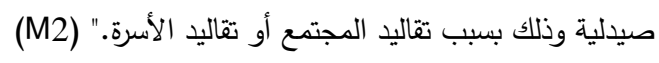


"... الدعم الذي يوفره المصرف للمرأة كان للنشاطات مثل الخياطة، النقش، التطريز، وصناعة الجبن والألبان

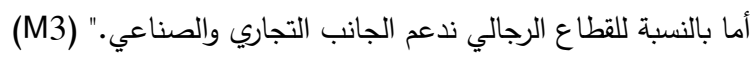

استتادا إلى آراء المشاركين؛ فإن العادات والتقاليد تمثل عائق رئيس ومشكلة شائعة في المجتمع اليمني أمام حصول

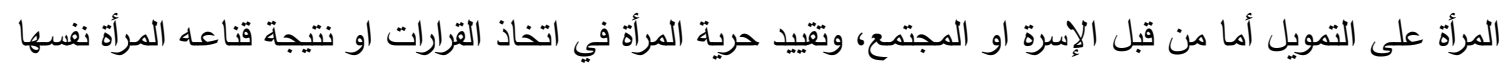

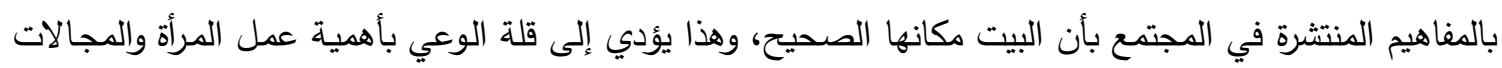

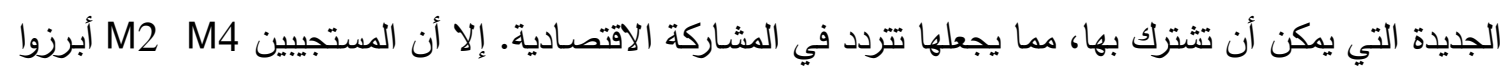

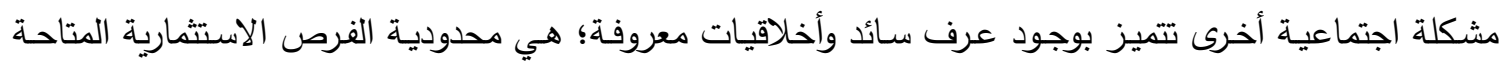

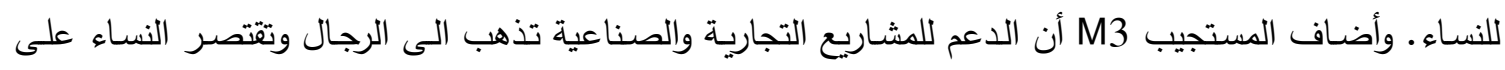
المشاريع الخدمية، وهذا بحد ذاته يثكل معضلة في تمكين المرأة اقتصاديًا.

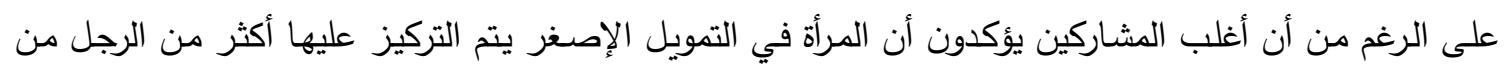

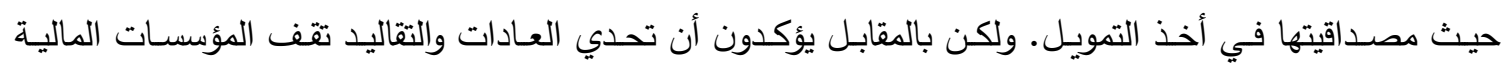
الإسلامية عاجزة أمامه.

\section{الموضوع الثاني Theme 2 : الأمية المالية للمرأة}

يستلزم لوجود نساء قادرات على تيسير دفة النشاط الاقتصادي، أن يكون لديهن وعي مالي ومصرفي، ولكن وفق

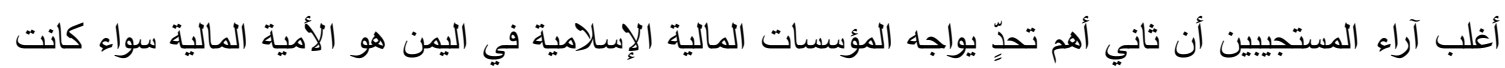
مصرفية أو تموليه أو تأمينية لاى النساء. استخدم المشاركون مصطلحات مختلفة للإشارة إلى الأمية المالية منها

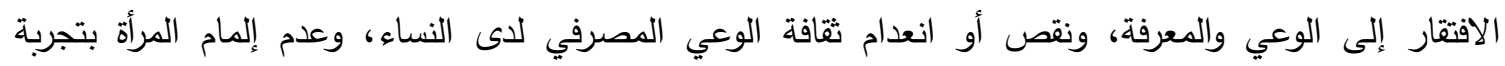

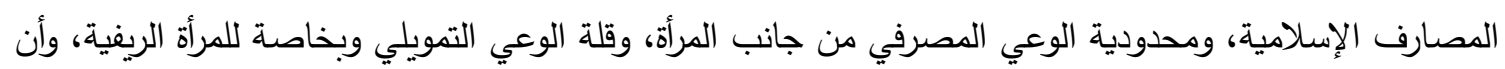

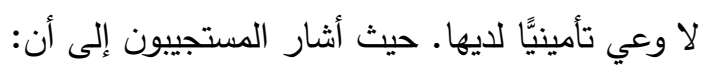

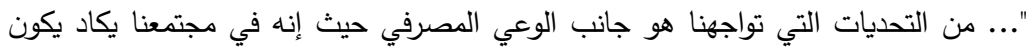

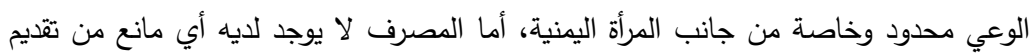

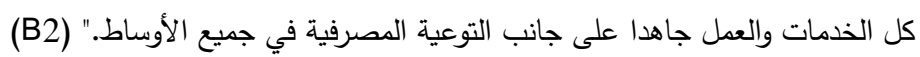
"... يوجد قصور في تمكين المرأة اقتصاديًا والسبب يعود إلى نقص وانعدام ثقافة الوعي

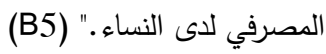

"... نظرا لعدم وجود وعي تأميني لا توجد أي بواليص تامين تصدر كوثيقة الحريق مثلا

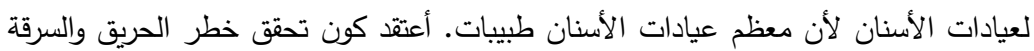

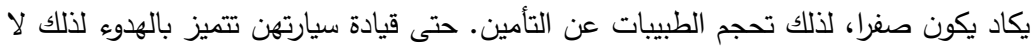

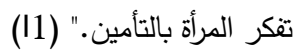
"... يعد التحدي الأكبر هو عدم الوعي التأميني والجهل بأهمية التأمين هو السبب الذي يقف وراء عدم التمات

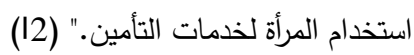


"... النساء مش عارفين وما عندهن فكرة أو توعية بالتمويل الأصغر ولسه الفكرة ما وصلت لهن، وكأن الفكرة مقصورة على الرجال، مثلا نزلت أكثر من مره واطرح لهن الفكرة ولكن هنالك تخوف من عملية استرداد المبلغ

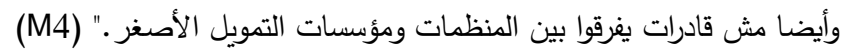

"... تعد الثقافة المصرفية تحدي حيث توصيل المعلومة للعميلة صعب، وبالذات إذا كانت العميلة أمية مثل التعريف بالمرابحة وطرقها وأساليبها، أما إذا كانت العميلة متعلمة يكون توضيح الفكرة أسهل." (B3)

"... نسعى إلى نشر عملية التمويل، وكنا نمول لحد 300 عميلة عن طريق المجموعات، عشر أشخاص نعملهم بمجموعة وكنا ندعم المهمشين ولكن الصعوبة هو كيفية توصل لهم المعلومة." (M3)

"... أغلبية النساء مشاريعهن مرتبطة بالبيت مثل الخياطة وصناعة البخور وغير ذلك، وما يقدرن يفرقن بين إيرادات المشروع ومصروفاته والمصروفات الثخصية، وفي النهاية يفشل المشروع." (M7)

"... أكبر مشكلة تواجه المرأة هو عدم قدرتها على إدارة نشاطها والتسويق له، أو ليس لها القدرة على التوسع، فتضطر إلى التوقف. أما أخذ التمويل يكون بيسر وبسهولة ويتم اعتبار النساء VIP ويتم معاملتهن معاملة خاصة." (M2) "... مع انعدام سبل الدخل وانقطاع الرواتب لجأت المرأة إلى البحث عن البديل لتحسين دخلها وإن اقتصر

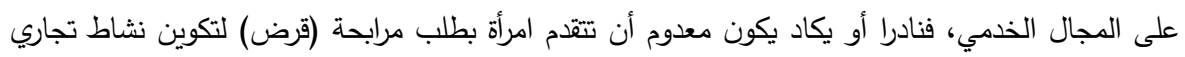
وذلك لتخوفها من المنافسة أولا ومن تقلبات الأسعار ." (B8)

"... عدم تقديم برامج التوعية وذلك بسبب عدم وجود الدعم لذلك. والوضع تقلص مع المشاكل نوعا ما. وحاليا

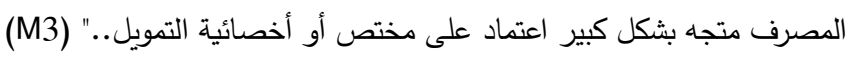
"... المصرف يعمل جاهدا على جانب التوعية المصرفية في جميع الأوساط، لكن برامج التوعية يقدمها المصرف وفقا المتاح حاليا وبجهد ذاتي." (B2) "... كان هناك برنامج تدريبية للمرأة ولكن توقف بسبب الأحداث ونتيجة الظروف الاقتصادية الموجودة وشحة

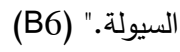


"... شركتا لم تقم يوما باستهاف النساء عدا التأمين على الحياة للمعلمات، النساء لسن ملاك لأعمال تدر

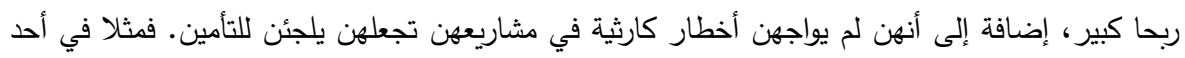

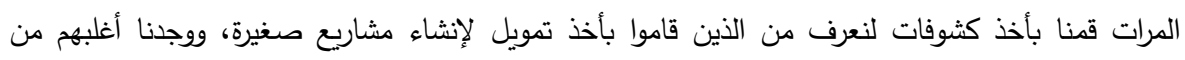

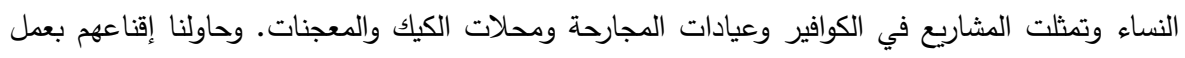

تأمين في حالة حدوث أي إصابات، والتأمين سيدفع كل الخسارة للطرف المتضرر ، لكنهم لم يقتنعوا."(11)

"... بالنسبة لليمن ليس للمرأة دور يخصها في التأمين إلا في بعض الحالات الثائعة مثل شمولها في وثيقة تأمين عامة لجميع موظفي الثركات. وفي في بعض الحالات النادرة مثل امتلاكها سيارة وتقوم بتأمينها فقط.

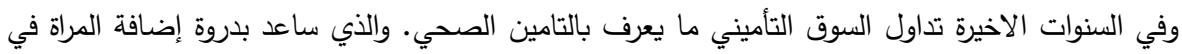

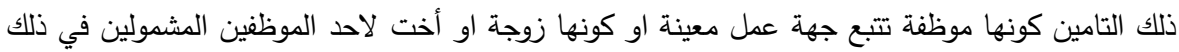

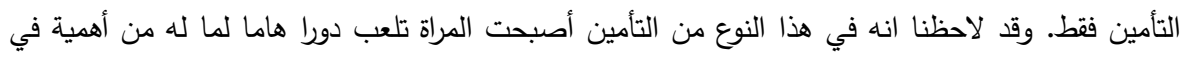

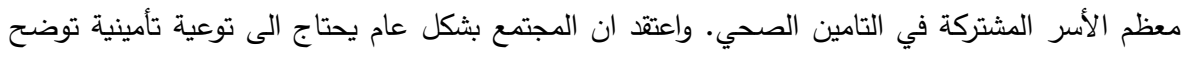

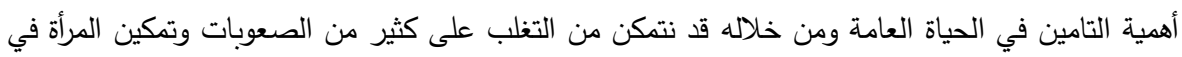

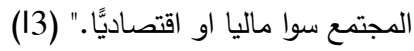

"... جانب آخر تنتقر المرأة للوعي والمعرفة. لأنه قد يكون الرجل أكثر اطلاع بحكم خروجه بين الناس أو لكأ

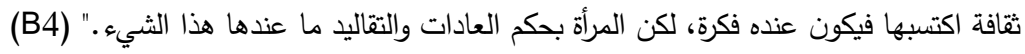

تعد الأمية المالية للمرأة تحديا لا يقل أهمية عن العادات والتقاليد، يؤدي إلى تقييد الفرص التمكينية اقتصاديًّا للمرأة، والتي من اهم أسبابها تدني المستوى التعليمي للمرأة، حيث 85\% من الرجال اليمنيين المتعلمين، فهناك 55 \%

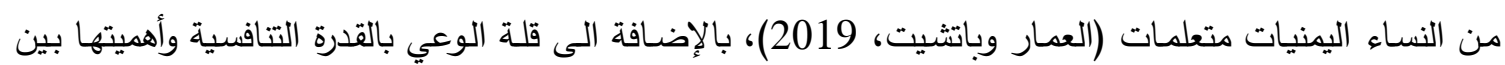
النساء مما يؤدي ذلك الى استبعادهن من المشاريع التجارية. أكد المشاركون أن المؤسسات المالية الإسلامية تعمل جاهدة في جانب التوعية المالية للمرأة ولكن ما زال هناك الك ندرة وتقليص لبرامج نشر وتعزيز الثقافة المالية والتمويلية والتأمينية، وعدم وجود أي دعم من الحكومة فية، مما يجعل المرأة

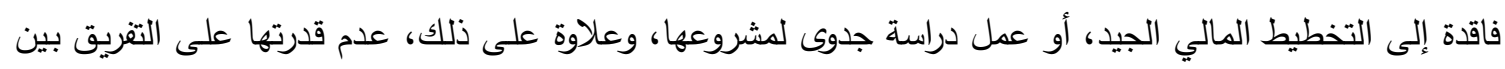

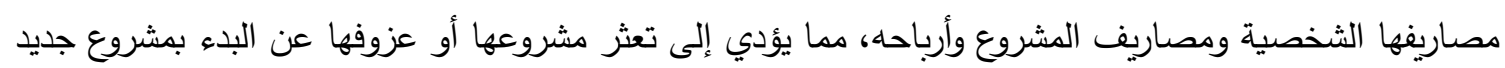

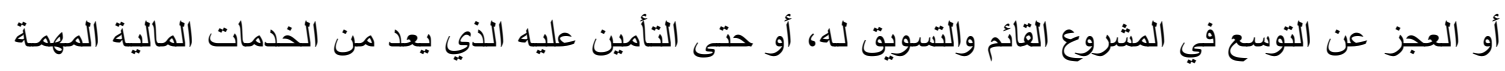

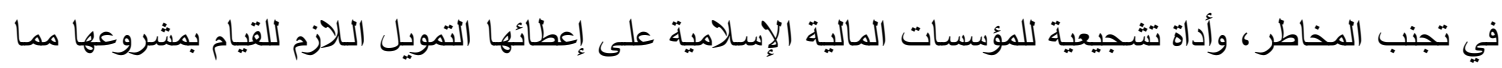

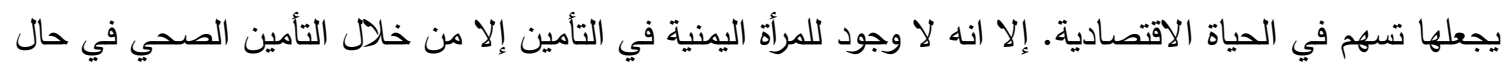

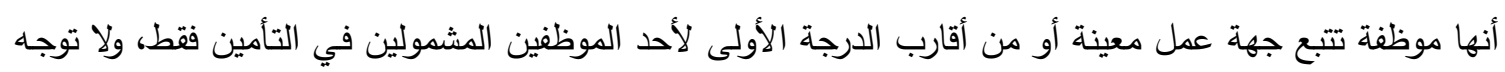

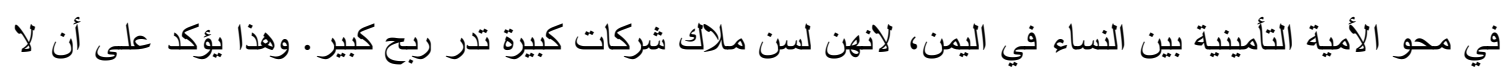

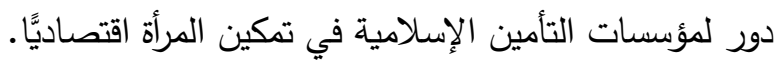


تطرق أحد المشاركين أن المجتمع بأكمله يحتاج إلى حملات توعوية تأمينية تسهم فيها شركات التأمين مع الحكومة لتوضيح أهمية التأمين في الحياة العامة للتغلب على كثير من الصعوبات وتمكين المرأة في المجتمع سوا ماليا او

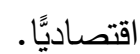

أكد اغلب المشاركين أنه على الرغم من أن النساء أكثر التزاما بسداد الأقساط التي عليهن في الوقت المحدد إلا أنه

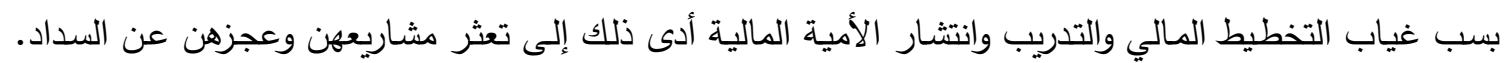
لهذا يمثلن قطاعاً عالي المخاطر (مجموعة البنك الدولي، 2018).

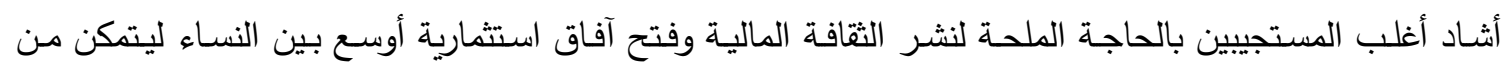

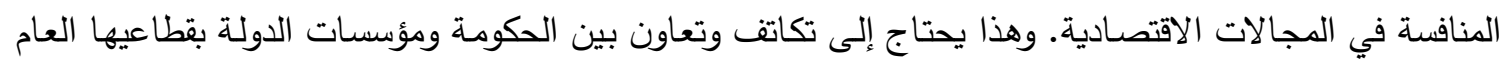

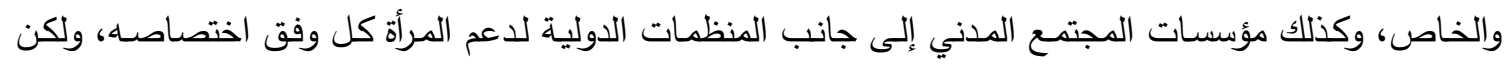

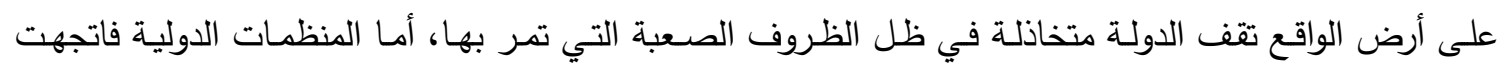

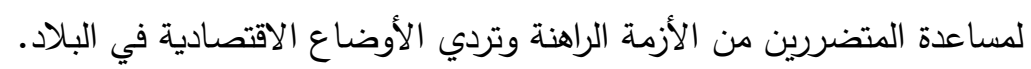

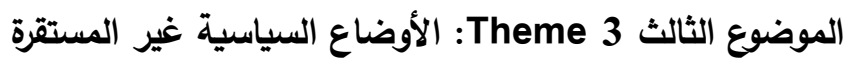

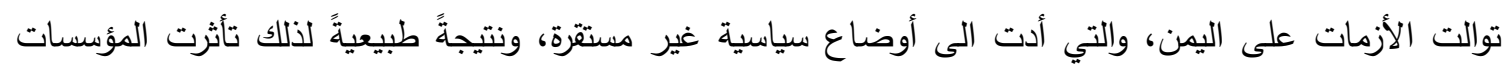

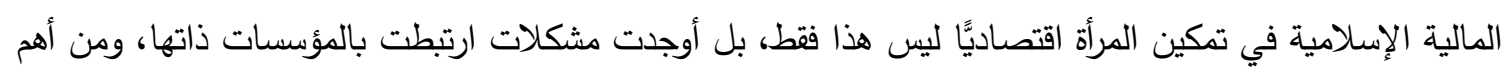
آراء المستجييين المتعلقة بذلك: الإسن

"... الأزمة الراهنة الموجودة في اليمن هي السبب الذي أبعدت المرأة عن الثمول الاقتصادي.

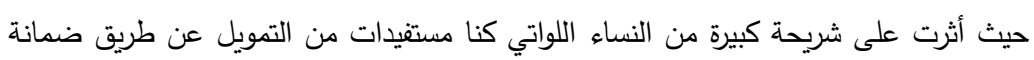

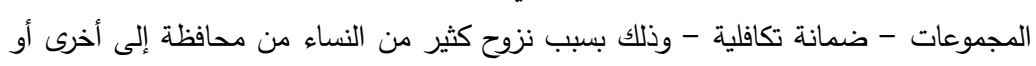

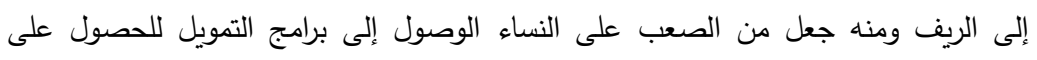

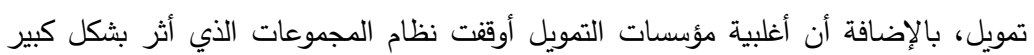

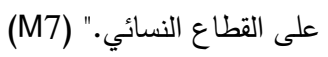
"... هناك شيء إيجابي وشيء سلبي. الإيجابي أنه كثير من اللواتي عندهن مشاريع ونشاطات في البيوت

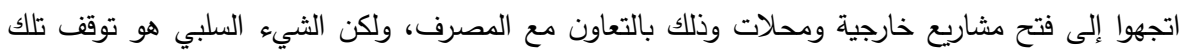

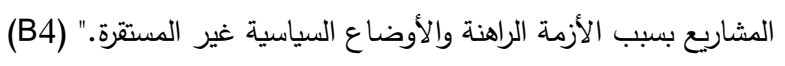

"... أول إثكالية واجهتها الدصارف في الفترة الحالية خاصة الثلاث السنوات أو الأربع السنوات

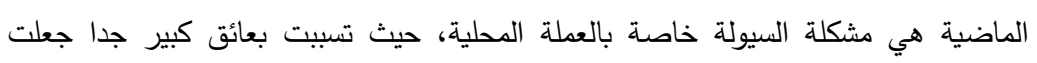

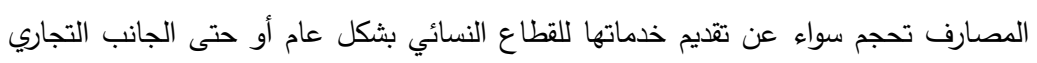

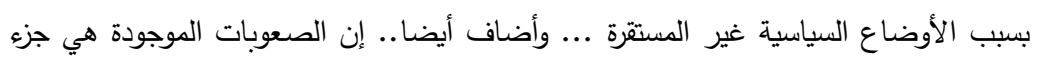

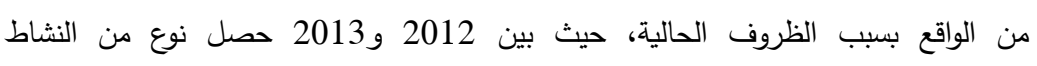

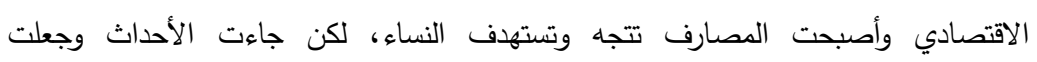

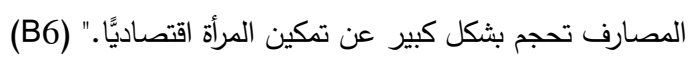

"... أكبر تحدي للمصارف عامة في تمكين المرأة اليمنية اقتصاديًا هو الوضع الحالي والأوضاع السياسية غير المستقرة." (B2)

"... المصرف بسبب الأوضاع مش قادر يمول بسبب الخوف من عملية التمويل لأنها لم تصبح

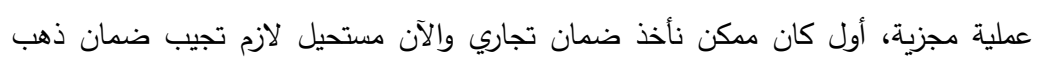


وأيضا غير مجدي بالنسبة للعميلة الثراء والوضع من دون رواتب وخاصة بالنسبة للنساء

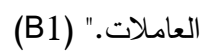

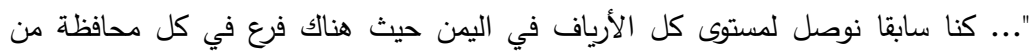

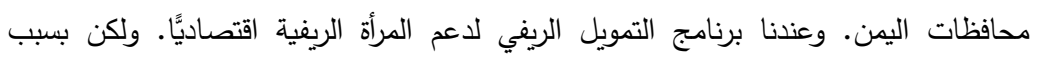

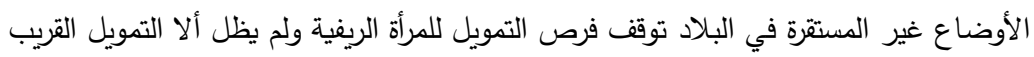

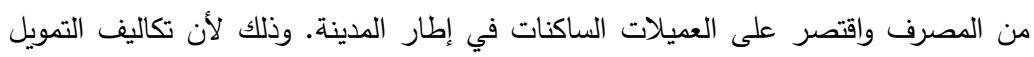

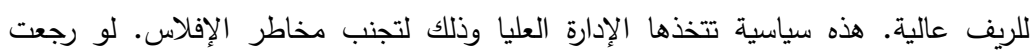

الأوضاع إلى ما كانت عليه بيمشي الوضع طبيعي." (M3)

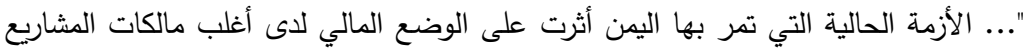

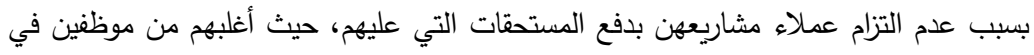
القطاعات المختلفة، وهؤلاء رواتبهم الثهرية غير منتظمة." (M6)

"... نزلنا إلى القرى، وما يعرفوا ثقافة الادخار المالي، وعملنا توعية بأهية الادخار المالي،

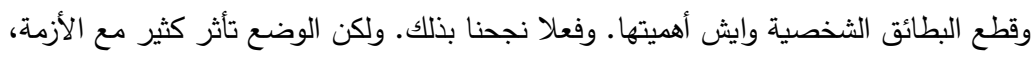

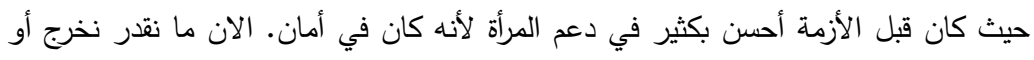

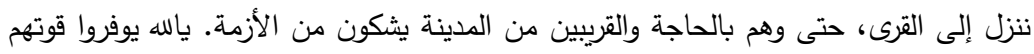

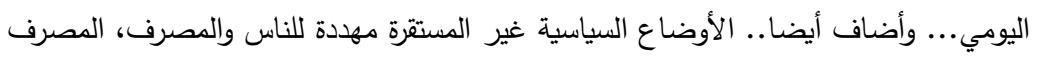

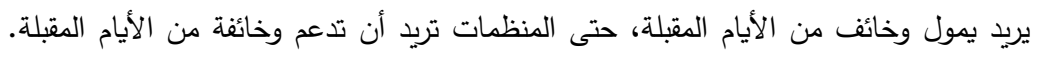

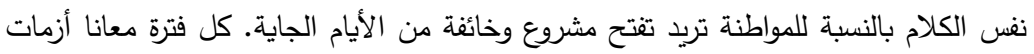

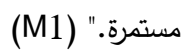

"... الأزمة ألقت بظلالها على كل المكونات الاجتماعية وخصوصا الطبقات المتوسطة

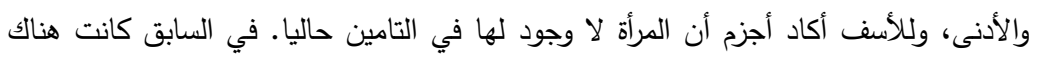

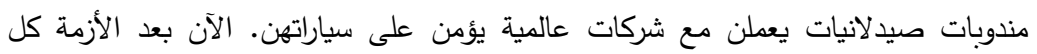

الثركات العالمية طلعت من اليمن. لذا معظمهن توقفن عن التأمين." (11)

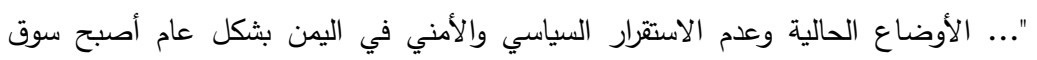

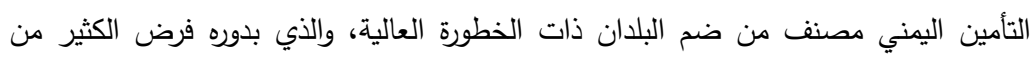

الأعباء المالية وارتفاع الأسعار التأمينية عالميا وخصوصا لدى الئ اليوق الئيني." (13)

وفق تعليقات المستجيبين أعلاه، كان لهم وجهات نظر وتصورات متثابه حول تحدي الأوضاع السياسية غير

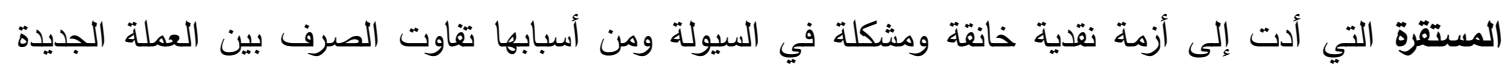
والقديمة بسبب انقسام السلطة في اليمن، مما نتج عنها التخوف من عملية التمويل والإحجام عن دعم المرأة

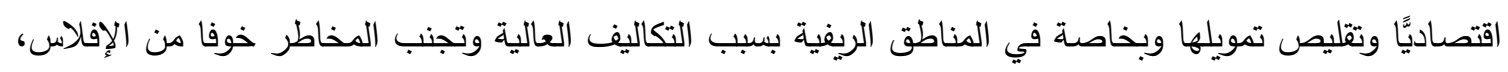

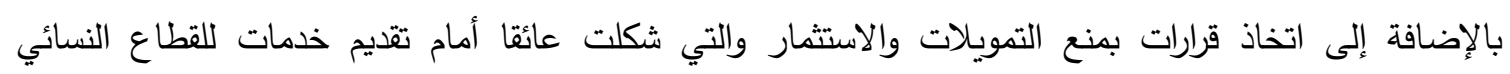
والتجاري بثكل عام. وعلاوة على ذلك توقف العمل بنظام المجموعات الذي أثر بثكل كبير على القطاع النسائي بالذات في مؤسسات التمويل الأصغر الإسلامي، وتوقف الطلب على التأمين بسبب خروج الثركات الأجنبية من اليمن. وهذا يؤكد على ارتفاع درجة المخاطرة، التي شكلت عبنًا على القطاع المالي في اليمن. 
أكد أحد المشاركين انه رغم الظروف التي تعرضت لها اليمن من سابق، إلا انه كان هناك مساعي لتحسين وضع المرأة ولكن الأزمة الراهنة والأوضاع السياسية غير المستقرة من بدايتها هي التي أحجمت تلكئك المساعي، وأشار المستجيبون إلى أهمية قبول العملة الجديدة، أو اعتماد إحدى العملتين، حتى تتحسن عملية التمويل وبخاصة للتمويل الريفي.

الموضوع الرابع Theme 4 الترفئ السياسات الحكومية

للحكومات دور مهم في اتخاذ الإجراءات والتدابير اللازمة والسياسات الفعالة لتمكين المرأة اقتصاديًّا، وتعزيز الوعي التيات المالي لديها، ولكن في اليمن هنالك غياب واضح لهذا الدور، وتم الإثارة إلى وجهات نظر بعض المستجيبين فيما يتعلق بهذا التحدي كما يأتي: ولئ ولين

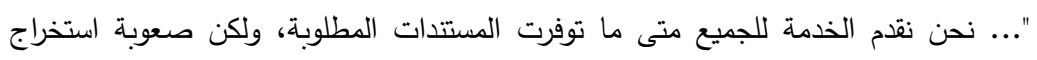

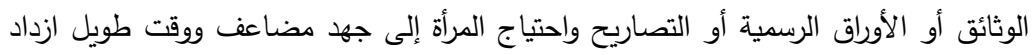

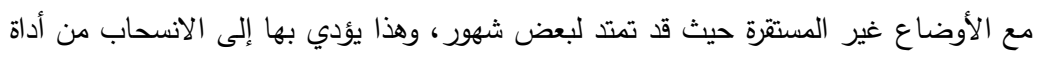

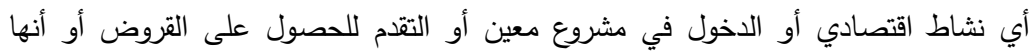

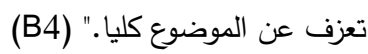

"... تكاليف استخراج البطاقة الثخصية غالية ويعد ذلك من التعقيدات لان قبل الأزمة كانت المرأة تجيب

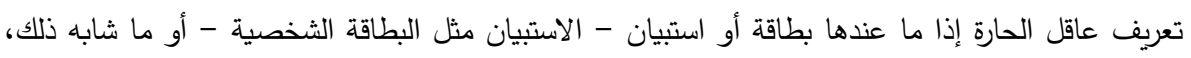

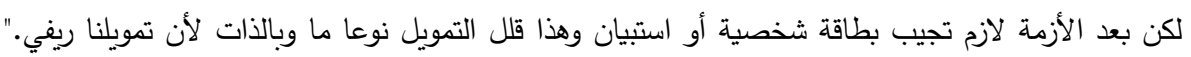

"... جهودنا من داخل المصرف ومساعدة منظمات دولية، ولا يوجد أي دعم من قبل الدولة، وأغلب مؤسسات

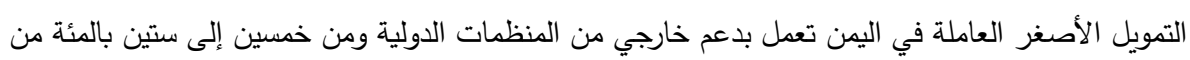
رأس مال يتبع الصندوق الاجتماعي للتنمية." (M3)

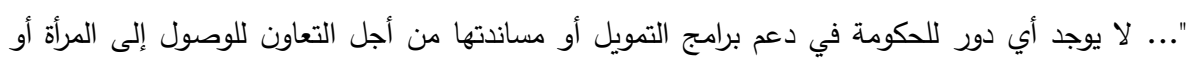

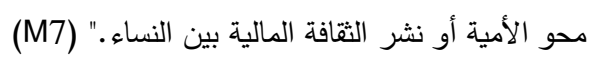
"... إطلاقا لا وجود أي توجه من قبل الحكومة أو مؤسسات المجتمع المدني على محو الأمية التأمينية بين

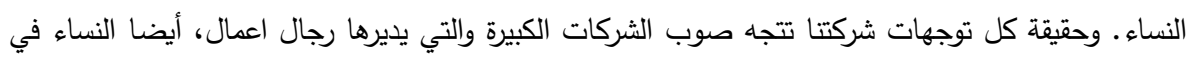
اليمن لم يدخلن قطاع كبير وتتحصر وجودهن في المشاغل والعيادات فقط" (11)

"... الصعوبات أنه لا يوجد دعم لهذا النشاط لأنه مكلف ويحتاج كادر نسائي، وأيضا المنظمات الداعمة لتمويل النساء توقفت واتجهت إلى التحويلات الاجتماعية لصرف الكساعدات الإنسانية الطارئة. التمويل

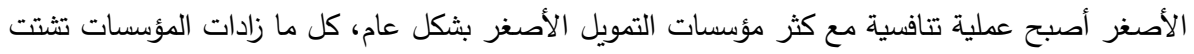

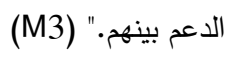

تبين من آراء المستجيبين أن السياسـات الحكومية أحد العوائق التي تحد المؤسسات المالية الإسلامية من تمكين

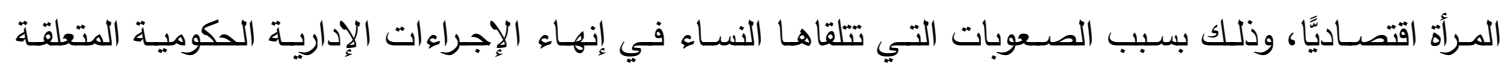

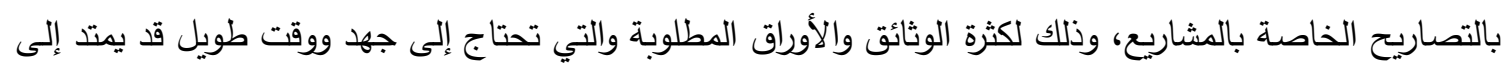

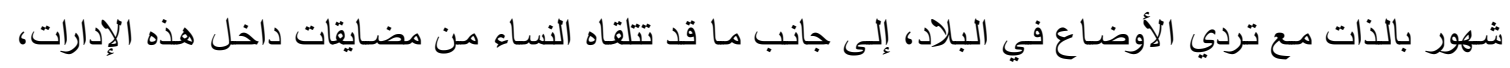


وارتفاع تكاليف المعاملات، كل هذا قد يؤدي بالنساء في أغلب الأحيان إلى الانسحاب من أداء أي نشاط اقتصادي أو الدخول في مشروع أو طلب الحصول على قرض، أو قد يؤدي إلى عزوفهن عن ذلك كليا، مما يتبين أن البيئة

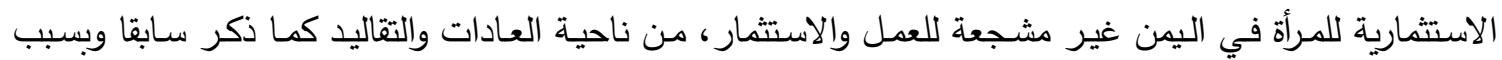

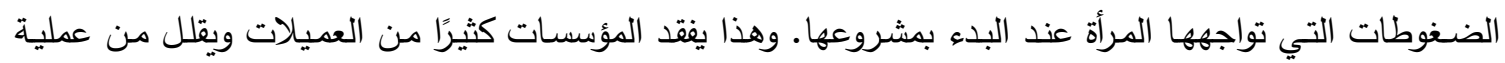
التككين لهن. علاوة عن ذلك أشار أغلب المشاركين إلى أن لا دور بارزًا للحكومة في عملية نشر الثقافة المصرفية والتمويلية والتأمينية لاى المرأة، أو أي دعم في إنجاح المؤسسات المالية الإسلامية وتحقيق الأهداف المرجوة منها، أو حتى محاولة الحد من تثتت الدعم الذي تم استقطابه وتوزيعه بشكل عادل. وأكد المشاركون على أهمية تسهيل

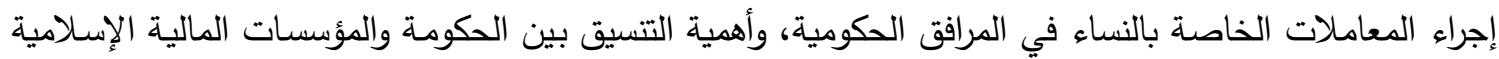

$$
\text { لنشر الوعي المالي بين النساء. }
$$

\section{الموضوع الخامس Theme 5 : محدودية الانتشار} يمثل محدودية الانتشار التحدي الذي يواجه المؤسسات المالية الإسلامية وهذا ما أكد عليه المستجيبين كالتالي:

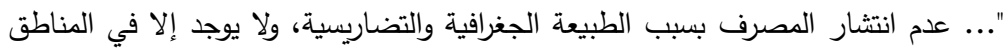

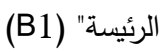

"... خدمات المصرف في المدن الرئيسة، وكان عند المصرف طموح في توسيع نطاق الخدمة لمناطق أكثر ولكن مع الأسف الوضع الحالي أدي للأحجام عن التوسع" (B2)

"... . كان لدى المصرف خطة للتوسع في جميع المحافظات قبل 2014 وفتح أكثر من فرع في المحافظة

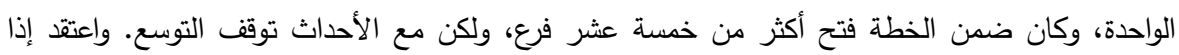

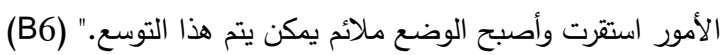

يعد الوصول إلى الخدمات المالية أكثر العناصر دعما للشمول المالي، وأداة لفتح الفرص الاقتصادية أمام رائدات الأعمال. ويمكن أن تكون نقاط الوصـول المالية المختلفة مثل الفروع المصرفية ومحطات نقاط البيع والوكلاء المصرفيين وأجهزة الصراف الآلي ومصارف التمويل الأصغر بوابة لاستخدام الخدمات المالية الإضافية التي يمكن أن تسمح بتطوير الأعمال التجارية من خلال الوصول إلى التسهيلات الائمانية (Fareed et al., 2017). ولكن حسب آراء بعض المستجيبين أن المؤسسات المالية الإسلامية تعاني من محدودية الانتشار في المديريات والريف الريف وهذا تحدّ يؤدي إلى إعاقة نشر الثقافة المصرفية والتمويلية والتأمينية، مما يدفع بكثير من المواطنين نساء ورجالاً

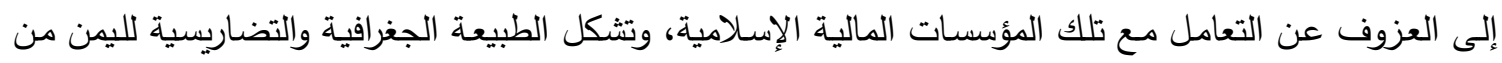
أسباب عدم انتشار المؤسسات المالية الإسـلامية، إلى جانب مـا شكلته الأزمـة في إحجام الكثير من المؤسسات الإنات المالية الإسلامية عن التوسع والانتشار وهذا يؤدي إلى إعاقة المجتمع كليا لا المرأة فقط.

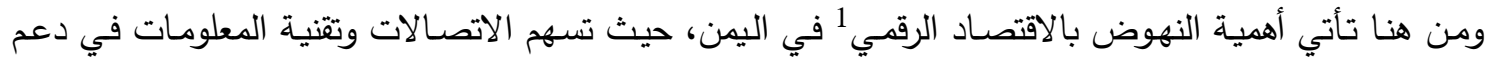

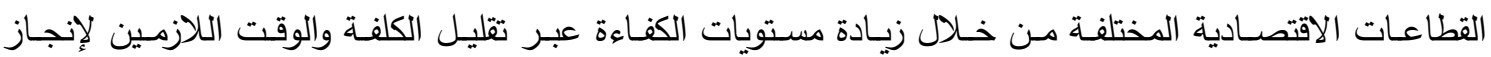
المعاملات الاقتصادية والمالية، وتحسين إنتاجية العمالة، وزيادة مستويات التنافسية (عبد المنعم وقعلول، 2021).

$1{ }^{1}$ الاقتصاد الرقمي: يمثل "جميع النشاطات الاقتصادية التي تعتمد على استخدام المدخلات الرقمية بما في ذلك التقنيات الرقمية، والبنية التحتية الرقمية،

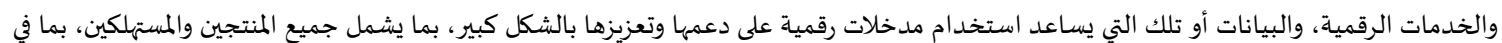
ذلك الحكومة" (عبد المنعم وقعلول، 2021). 
فتحت التطورات المصـرفية الجديدة عبر الهاتف المحمول واستخدام الخدمات الماليـة عبر الإنترنت بابًا جديدًا للخدمات المالية الرسمية للتغلب على عائق المسافة واتساع فرص الوصـول للخدمات المالية. وبخاصـة بالنسبة

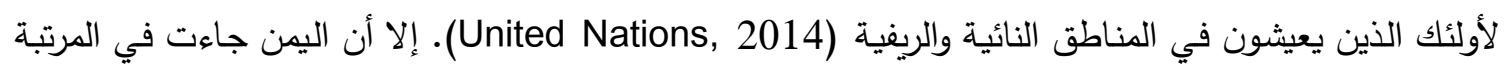

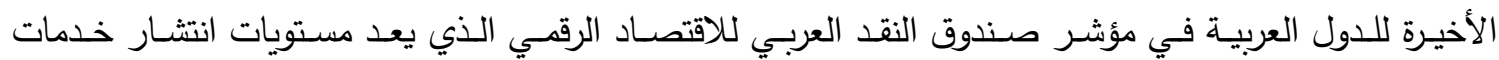

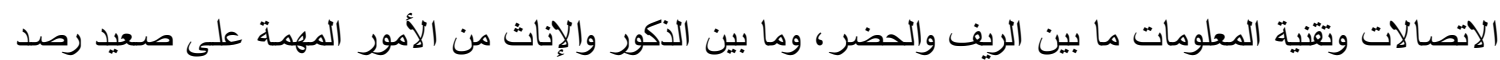

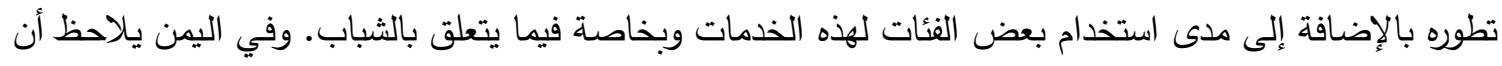

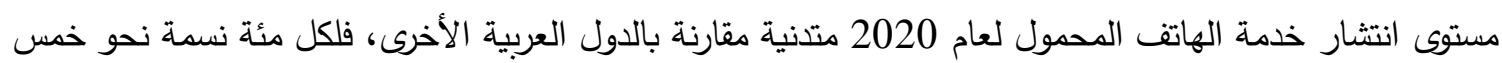
اشتراكات فقط (عبد المنعم وقعلول، 2021).

الموضوع السادس Theme 6 : محدودية الاخل للمرأة يعد محدودية الدخل للمرأة من التحديات التي تواجهه المؤسسات المالية الإسلامية في تمكين المرأة اقتصاديًّا عند

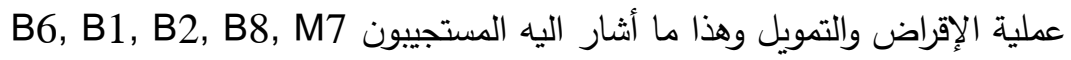

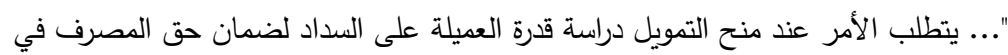

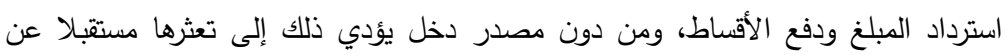

(B8) (السداد. (B)

"... أغلب برامج التمويل ومؤسسات التمويل الأصغر هدفها الوصول إلى شريحة أكبر من النساء ولكن

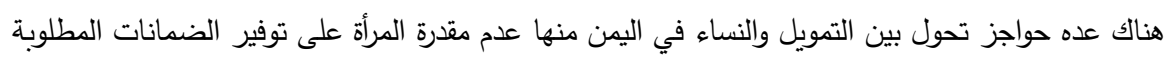

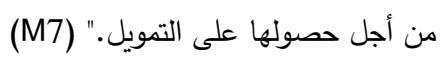

"... لا يقدم الدصرف خدمة التمويلات لأي فئة إلا بعد عمل الدراسة اللازمة واخذ الضمانات الكافية،

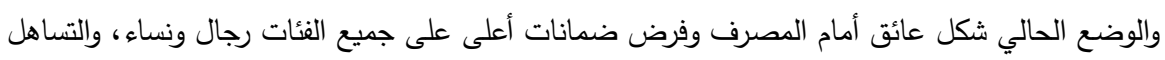

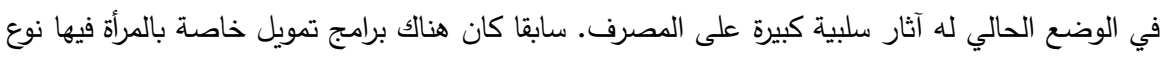
من التسهيل بموضوع الضمانات." (B2)

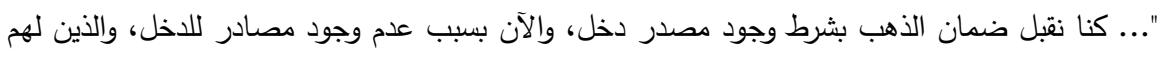

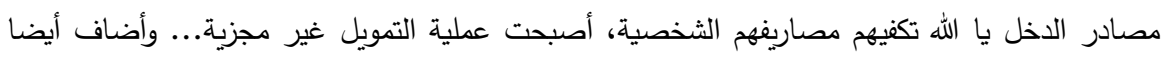

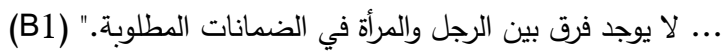

أكــ أغلب المسـتجيبين أن إجـراءات الحصـول على التمويـل أو أي مـن الخـمات الماليـة الأخـرى المقدمـة مـن

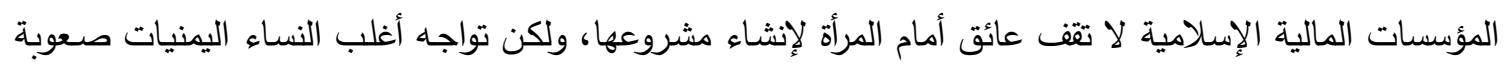

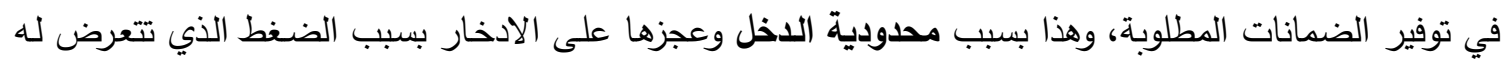

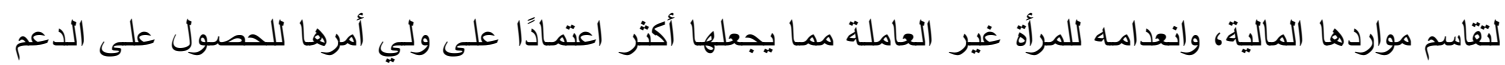
المالي؛ وارتفاع معدل الفقر في البلاد وغيرها، وأكد المشاركون أن هذا يجعل منه عائقًا يواجه المؤسسات المالية المهات

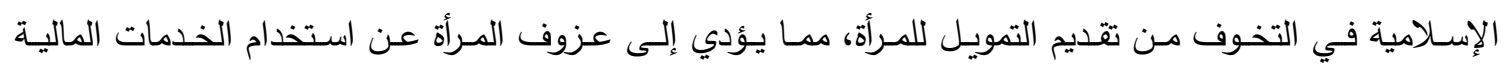
الإسلامية، وإخراجها من الحياة الاقتصادية. لهذا تتبع أهمية خلق فرص جديدة للمرأة وبخاصة في الجانب الصناعي عندي 
والإنتاجي حتى تتمكن من تأمين مصدر دخل ثابت، ويرتد ذلك على الاقتصاد الوطني، وألا يقتصر طلبها للخدمات المالية على الجانب الاستهلاكي.

الموضوع السابع Theme 7 : التصورات الدينية الخاطئة إن تطبيق أحكام وقواعد الثريعة الإسلامية في معاملات ونشاطات المؤسسات المالية الإسلامية أمر جوهري وأساس طالما أن هذه المؤسسات تعمل تحت شعار من دون فائدة، والنظام الإسلامي والنظام الربوي متتاقضسان في التصور

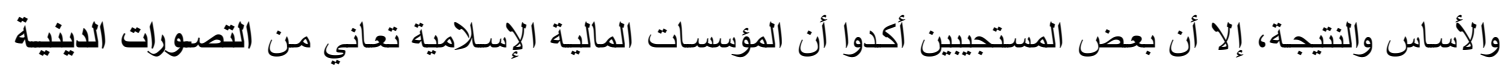

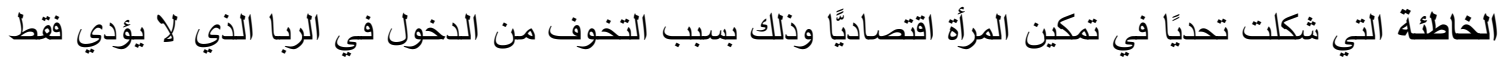

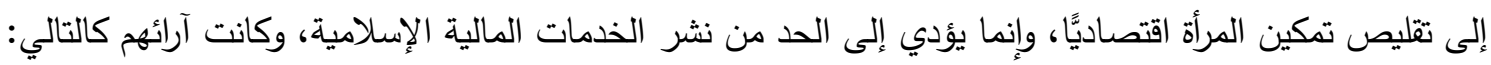

$$
\begin{aligned}
& \text { "... من أكثر المعوقات بالنسبة لتككين النساء هو تخوفهن من الدخول في الربا، على الرغم من الرنا }
\end{aligned}
$$

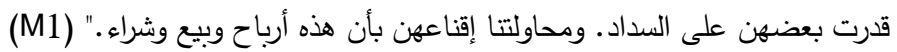

"... العائق الذي يواجهنا في عملية التمويل هو وجود شخص متثدد دينيا، يقول هذا ربا على طول مباشرة

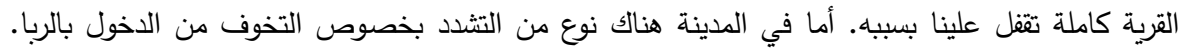

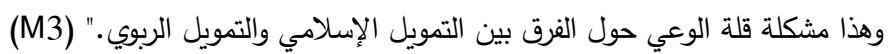
"... عدم وجود الوعي من قبل الأفراد والدجتمع بخصوص التمويل. يعنى أنكا أخذت تمويل فانت دخلت

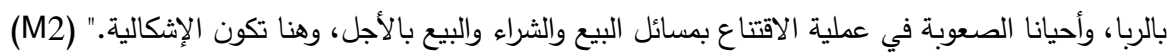
"... هناك تصور لدى بعض الناس أن التأمين عبارة عن نصب واحتيال فهرد أن تدعوهم إلى التأمين

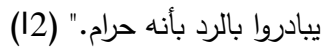

تعزى تلك التصورات الدينية الخاطئة إلى عدم إلمام النساء بالفرق بين المؤسسات المالية الإسلامية والتقليدية. على

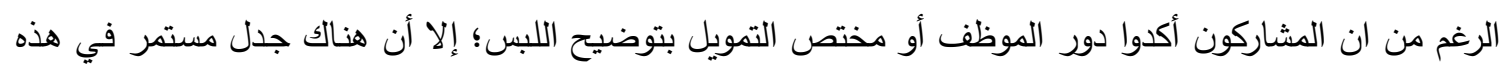
المسألة؛ لأنه إذا وجد شخص متثند في مكان معين يقول إن التعامل مع المؤسسات المالية الإسلامية فيه شبه ربا، فسيتوقف كل من حوله عن التعامل مع تلك المؤسسات وليس النساء فقط.

الموضوع الثامن Theme 8 : محدودية الترويج والإعلان تقوم المؤسسات المالية الإسلامية عبر إستراتيجية الترويج بجذب وخلق الوعي بين الناس لاستخدام منتجاتها وخدماتها. ويعد الترويج أحد الوسائل المستخدمة لنشر وزيادة حصتها في السوق. وتتضمن هذه الإستراتيجية أدوات متنوعة مثل الإعلان من خلال وسائل مختلفة مثل التلفزيون والراديو والمجلات والصحف واللوحات الإعلانية والملصقات...إلخ. بالإضافة إلى البيع والتسويق المباشر والتحويل الإلكتروني والعلاقات العامة وما إلى ذلك (محمود، 2019). لهذا يجب مراعاتها في المؤسسات المالية الإسلامية وذلك للمنافسة الثرسة التي تواجهها من نظيرتها التقليدية، حيث تعد من الوسائل الفعالة لجذب وخلق الوعي بين جميع فئات المجتمع بالذات النساء لشراء منتجاتها واستخدام خدماتها. لهذا تطرق بعض المشاركين لمحدودية الترويج والإعلان كتحد يواجه المؤسسات 
المالية الإسلامية في تمكين المرأة اقتصاديًا، وأكدوا على ندرة الترويج الإعلامي واقتصاره على التسويق المباشر عبر

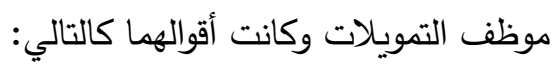

الموظفين أنفهم هو الذي يساعد للترويج الإعلامي المتقروء والمسموع، فالترويج الميداني عن طريق العماء، ويعد موظف التمويلات هو الركيزة

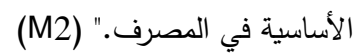

"... ندرة وجود التوعية والترويج إعلاميا عبر وسائل الإعلام المختلفة المرئية والمسموعة مثل التلفزيون

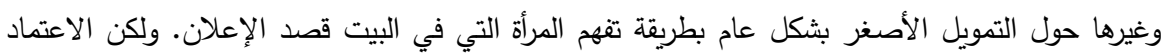

كله على مختص أو إخصائية التمويل." (M3)

"... تعتمد عملية الدعاية والترويج والتسويق الميداني على موظفات المصرف، وقام المصرف بعمل دعاية

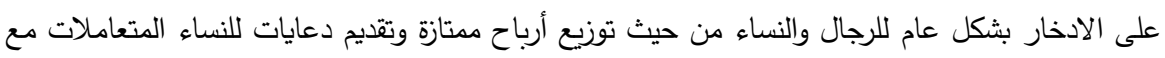
المصرف مثل هدايا تخص النساء، علثان يثجع النساء على أن تحتفظ بأموالهن لدى المصرف. ولكن هذا لا يكفي ويجب أن يكون هناك نزول إلى المدارس والجامعات وعمل ترويجي لأهمية استخدام الخدمات

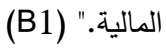

الجدير بالذكر التتبيهـ إلى أن الأدبيات السـابقة تعـج بالتحديات التي تواجـه المؤسسـات المالية، إلا أن أهميـة تلك التحديات ومسبباتها قد تتنوع وتتعدد حسب الظرف والزمان والمكان، بل حسب خلفية الباحثين أنفسهم. وإذا كانت العادات والتقاليد مثلاً حسب نتائج دراستتا الحالية هي أهم تحدٍّ يواجه المؤسسات المالية الإسلامية في تمكين المرأة اقتصاديًا، فإن محدودية الانتثار قد تكون الأهم وراء المشكلة نفسها على افتراض تطبيق هذه الدراسة في بدايات ظهور المؤسسات المالية اليمنية الإسلامية في التسعينيات. تم ترتيب التحديات والصعوبات حسب الأهمية بالنسبة للمستجيبين، وذلك حتى يسهل على صناع السياسات وضع الحلول واتخاذ القرارات الصحيحة والمناسبة حسب كل تحدّ ومراعاة الأوضاع الذي تمر به اليمن. فلا نسعى مثلاً في بذل الجهد لعمل مقترحات عن كيفية إيجاد الحلول لتسهيل الإجراءات الحكومية للمرأة، في ظل غياب الدولة وانعدام الأمان. لهذا وجب مراعاة الزمان والمكان والظرف، لأنه ما كان مشكلة بالأمس، قد يكون حل اليوم. لذا وبناء على ما تم مناقشته، استخلصت الدراسة الاقتراحات التالية: تفعيل دور الإلزامية في المجتمع وفرض العقوبات على من يخالفها، وذلك لمحاولة معالجة الموروث الثقافي التمييزي ضد المرأة وذلك من خلال إجراءات عدة منها إلزامية التعليم للمرأة من المرحلة الابتدائية حتى الجامعية، حيث وليث يلاحظ أن نسب التحاق الإناث بالتعليم في اليمن تتتاقص حسب المرحلة التعليمية (صندوق النقد العربي، 2020)،

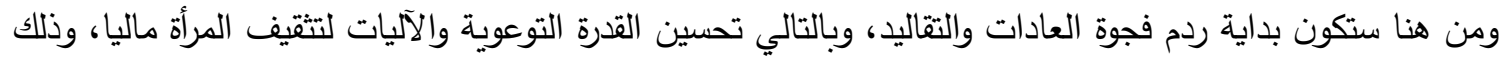

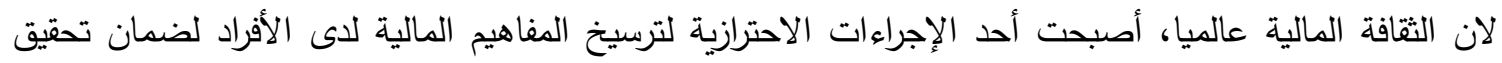
الثمول المالي (شنبي وبن لخضر، 2018) الذي يعتبر أحد الاستراتيجيات المهمة في تمكين المرأة اقتصاديًّا

.(Demirguc-Kunt et al., 2018; Islam, 2014; Isaac, 2014; ) فتح آفاق جديدة لتكافؤ الفرص الاستثمارية للمرأة من خلال إثراكها في المجالات المهيمن عليها الرجال مثل مجالات الهندسة، التكنولوجيا، والصيانة الإكترونية... إلخ. وخلق فرص جديدة للمرأة بالجانب الصناعي والإنتاجي، 
حيث تثير آخر إحصائيات إلى أن مشاركة المرأة اليمنية في قوة العمل لقطاع الزراعة عام 2018 نسبة 47.12٪ مقارنة بقطاع الخدمات 22\%، وقطاع الصناعة 10.71\% (صندوق النقد العربي، 2020). تفعيل دور التأمين الإسلامي في المجتمع وبالذات للنساء، وذلك من خلال إلزام سيدات ورائدات الأعمال والمشاريع

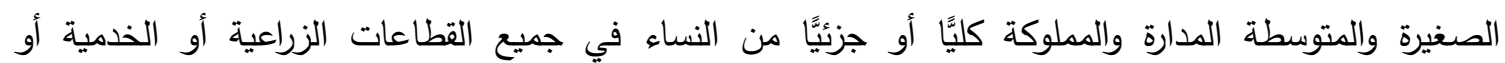

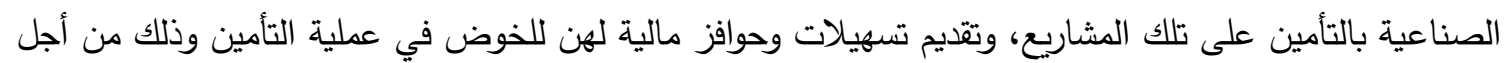
تفادي مخاطر تعثر وأغلاق المشروع، وبناء الثقة في عملية الحصول على تُعلى التمويل. بناء إستراتيجية وطنية للثمول المالي الإسلامي ليس في اليمن فقط ولكن في جميع البلدان الإسلامية، تهدف إلى فئى

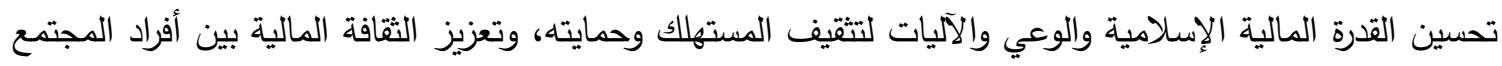
المسلم بدءًا من طلبة المدارس عبر حملات توعوية تتم بالتعاون بين مزودي الخدمات المالية الإسلامية والجهات

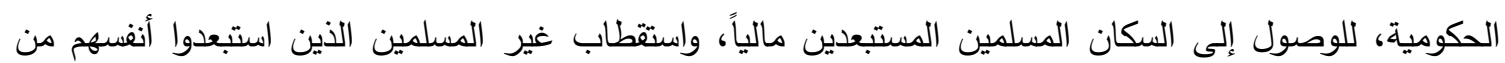
الأنظمة المالية التقليدية. بالإضافة الى أهمية إصدار فتوى شاملة للمجتمع بأكمله تزيح اللبس والتخوف من التعامل مع المؤسسات المالية الإسلامية والجدل المستمر في مسالة الربا. ضرورة تعزيز وتطوير البنية الأساس لقطاع الاتصالات وتقنية المعلومات بما يساعد على الاهتمام بتوفير تلك الكانك

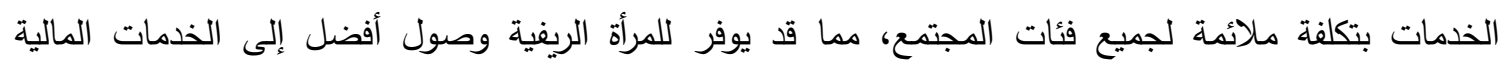
الإسلامية، وذلك بسبب محدودية الانتثار في القرى التي تثكل تحديًا في تمكين المرأة اقتصاديًا.

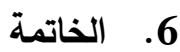

خلصت الدارسة الى ثمان تحديات تواجه المؤسسات المالية الإسلامية في التمكين الاقتصادي للمرأة في اليمن، وتم

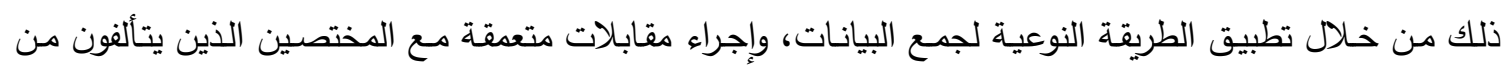

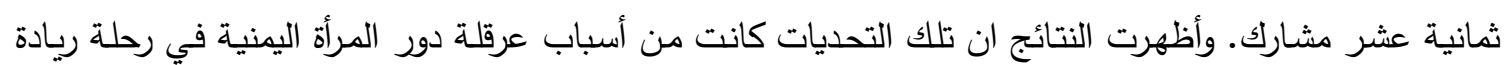

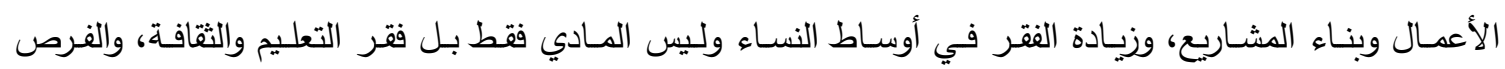

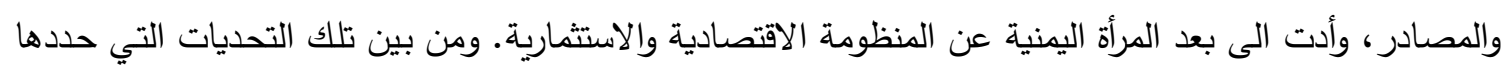
المستجيبون العادات والتقاليد، والأمية المالية، والأوضاع السياسية غير المستقرة، ومحدودية الدخل للمرأة وغيرها؛

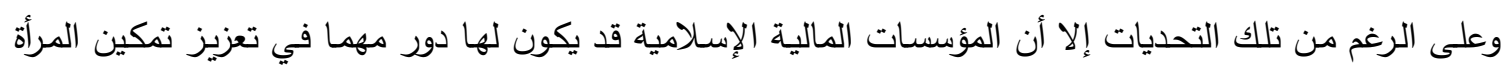

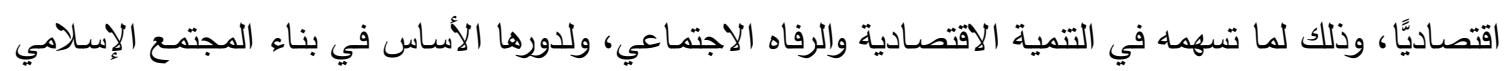
في عصوره الزاهرة. ترتب على هذه الدراسة مساهمة نظرية من خلال إضافة معرفية واقعية لأدبيات البحث في السياق اليمني. اما إسهامها في الجانب العملي فتعتبر مصدر أساس لصانعي السياسات لإيلاء مزيد من الاهتمام بتصميم سياسات تدعم المؤسسات المالية من جهة وحق المرأة في التعليم والعمل من جهة اخري.

7. حدود البحث ومزيد من المجالات البحثية المستقبلية

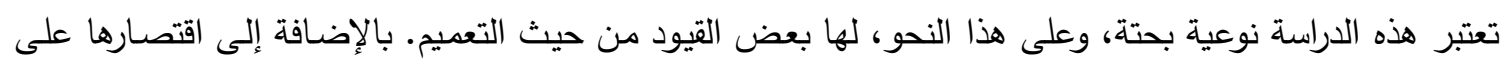

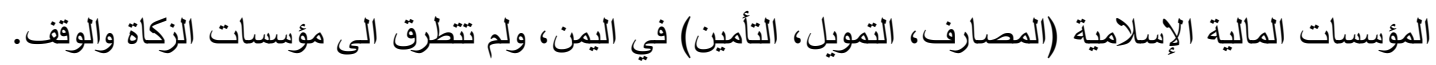

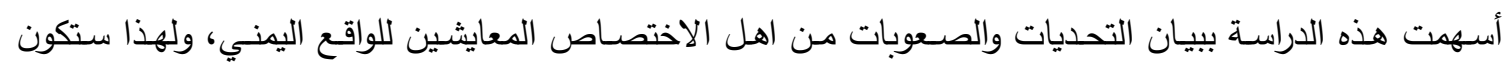

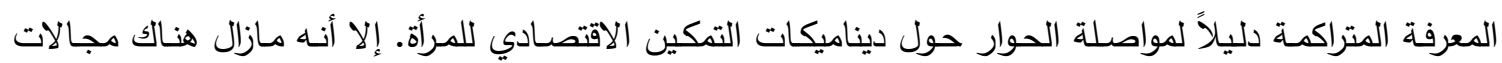


مهمة لمزيد من البحث، حيث بالإمكان ان تركز الأبحاث المستقبلية على وجهة نظر المرأة لتحديد الأسباب الحقيقة التي تقف وراء تصاعد معاناتها ويتم مقارنته بنتائج هذه الدراسة، لتقديم منظور مختلف عن عن معوقات تمكين المرأة اقتصاديًّ في اليمن. بالإضافة الى عمل دراسة مقارنة بين تمكين المرأة في الاقتصادات المتطورة والنامية والأقل نمواً مـن حيث أوجـه الثـبة والاختلاف. وإجـراء دراسـة عن دور مؤسسـات الزكاة والوقف في في تمكين المـرأة اقتصـاديًّا والتحديات التي تواجهها في ذلك.

أحمد السيد محمد رمضان. (2019). التتمية المستدامة والثمول المالي: الرؤى والأثار والتداعيات. المؤتمر العلمي الثالث لكلية التجارة. جامعة طنطا.

https://www.yiic.co/ الإسلامية للتأمين. (2021). عن الإسلامية للتأمين.

أشرف محمد دوابه (2016). رؤية استراتيجية لمواجهة تحديات التأمين التكافلي الإسلامي. مجلة الاقتصاد والتمويل

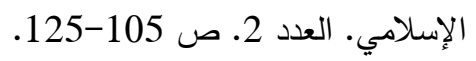

https://bit.ly/3600r5W الإمام محمد محمود. (2019). البنوك الإسلامية واستراتيجيات التسويق. موقع إسلام اولاين.

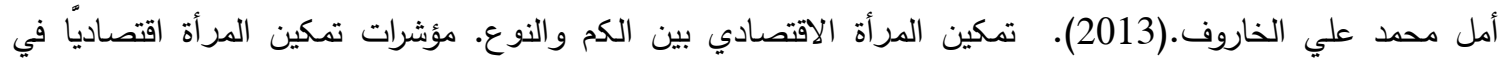
الأردن. الصندوق الأردني الهاشمي للتنمية البشرية. الأردن.

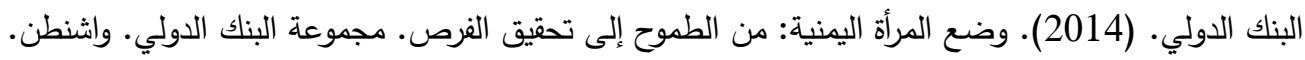

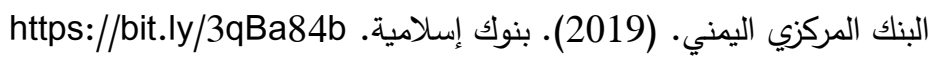
جمعية البنوك اليمنية.(2020). أمين عام الاتحاد اليمني للتأمين: عمر التأمين في اليمن يتجاوز الـ 150 عاماً. موقع جمعية https://bit.ly/2UzwuHi .2020/11/28 البنوك اليمنية.

https://bit.ly/2Tc9cqz الراي. (2014). التمويل الإسلامي يمنح قيمة مضافة للشمول المالية سيد قطب. (1995). تقسير آيات الربا. دار الثروق. القاهرة.

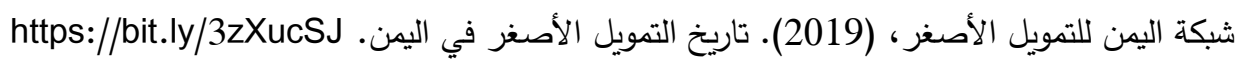

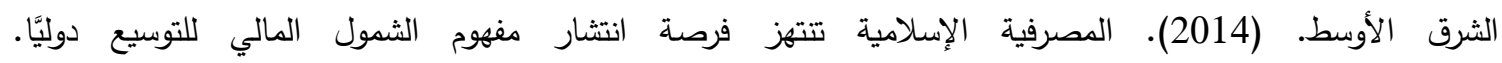
https://bit.ly/3h9ObVE

صندوق النقد العربي (2020). دور صندوق النقد العربي في تمكين المرأة العببة. أبو ظبي.

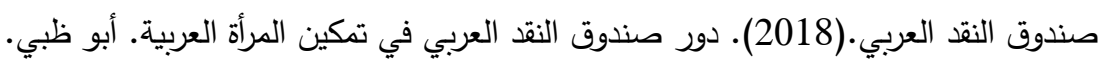

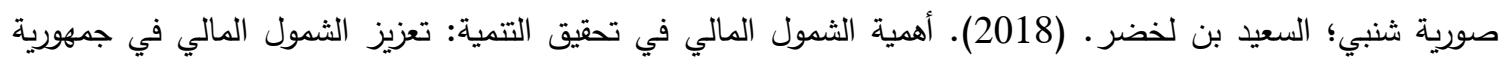

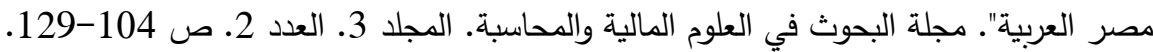

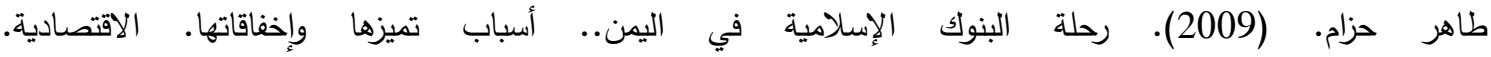
https://www.aleqt.com/2009/07/09/article_250322.html

عبد الرحيم عبد الحميد الساعاتي. (2012). العلة الاقتصادية لتحريم ربا النسيئة والفضل. مجلة جامعة عبد الملك عبد العزيز • الاقتصاد الإسلامي. 2/25.

فؤاد عبد الله العمر • (2003). مقدمة في تاريخ الاقتصاد الإسلامي وتطوره. المصرف الإسلامي للتنمية. المعهد الإسلامي للبحوث والتدريب. البحث رقم 62. ط1. جدة.

فوزية العمار؛ هانا باتثيت. (2019). اليمن: تداعيات الحرب على القوى العاملة من النساء. مركز صنعاء للدراسات https://bit.ly/3wZTygV الإستراتيجية. 


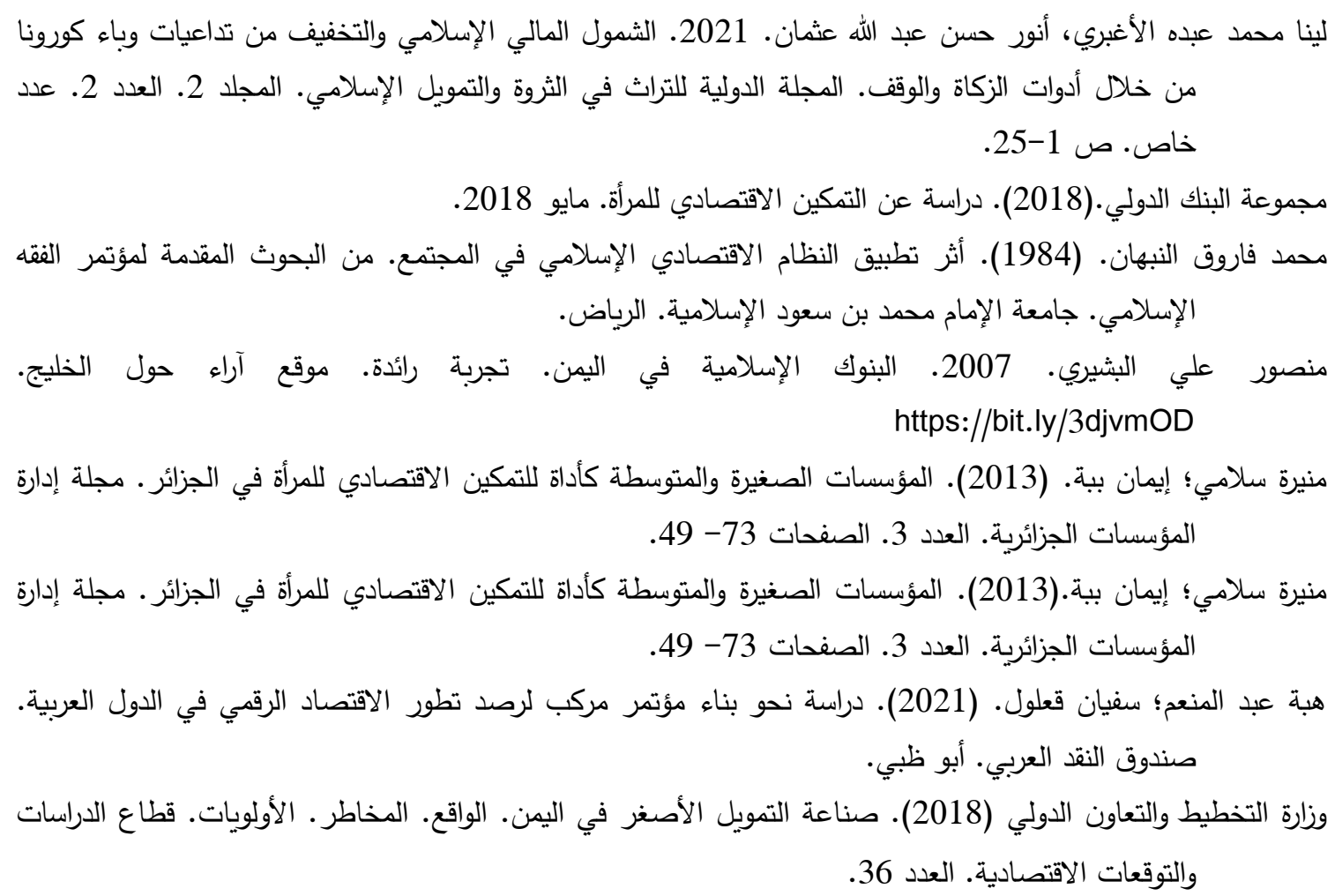

\section{References}

Ahmed, H. (2002). Financing microenterprises: An analytical study of Islamic microfinance institutions. Islamic economic studies, 9(2). 27-64.

Ali, A. E., (2019). Empowering women through financial inclusion: Some evidence from Comoros. International Journal of Asian Social Science, 9(2), 256-270. https://doi.org/10.18488/journal.1.2019.92.256.270

Alshebami, A. S., \& Khandare, D. M. (2014). Microfinance in Yemen "Challenges and Opportunities. International Journal in Management and Social Science, 2(12), 400-413. https://doi.org/10.5296/ijsw.v2i2.7937

Alshebami, A. S., \& Khandare, D. M. (2015). The role of microfinance for empowerment of poor women in Yemen. International Journal of Social Work, 2(1), 36-44. https://doi.org/10.5296/ijsw.v2i1.7752

Alshebami, A. S., \& Rengarajan, V. (2017). Microfinance Institutions in Yemen "Hurdles and Remedies". International Journal of Social Work, 4(1), 10. https://doi.org/10.5296/ijsw.v4i1.10695

Braun, V. \& Clarke, V. (2012) Thematic analysis. In H. Cooper, P. M. Camic, D. L. Long, A. T. Panter, D. Rindskopf, \& K. J. Sher (Eds), APA handbook of research methods in psychology, Vol. 2: Research designs: Quantitative, qualitative, neuropsychological, and biological (pp. 57-71). Washington, DC: American Psychological Association. https://doi.org/10.1191/1478088706qp063oa

Braun, V., \& Clarke, V. (2006). Using thematic analysis in psychology. Qualitative research in psychology, 3(2), 77-101.

CGAP, (2017). Humanitarian Crises: Financial Services Can Improve Resilience. https://bit.ly/2Uasn48

Demirguc-Kunt, A., Klapper, L., \& Randall, D. (2013). Islamic finance and financial inclusion: measuring use of and demand for formal financial services among Muslim adults. Policy Research Working Paper 6642. https://doi.org/10.1596/1813- 


\section{0-6642}

Demirguc-Kunt, A., Klapper, L., Singer, D., Ansar, S., \& Hess, J. (2018). The Global Findex Database 2017: Measuring financial inclusion and the fintech revolution. The World Bank.. Washington, DC: World Bank. https://doi.org/10.1596/978-14648-1259-0

Fareed, F., Gabriel, M., Lenain, P., \& Reynaud, J. (2017). Financial inclusion and women entrepreneurship: Evidence from Mexico. https://doi.org/10.1787/2fbd0f35en

Guest, G., Bunce, A., \& Johnson, L. (2006). How many interviews are enough? An experiment with data saturation and variability. Field methods, 18(1), 59-82. https://doi.org/10.1177/1525822X05279903

Hassan, A. (2015). Financial inclusion of the poor: from microcredit to Islamic micro financial services. Humanomics. 31(3), 354-71. https://doi.org/10.1108/H-07-2014$\underline{0051}$

Hassan, A., \& Saleem, S. (2017). An Islamic microfinance business model in Bangladesh: Its Role in Alleviation of Poverty and Socio-Economic Well-Being of Women'. Humanomics, 33(1), 15-37. https://doi.org/10.1108/H-08-2016-0066

Hassan, M. K., Rabbani, M. R., \& Abdulla, Y. (2021). Socioeconomic Impact of COVID-19 in MENA region and the Role of Islamic Finance. International Journal of Islamic Economics and Finance (IJIEF), 4(1), 51-78. https://doi.org/10.18196/ijief.v4i1.10466

Holloway, K., Niazi, Z., \& Rouse, R. (2017). Women's economic empowerment through financial inclusion: A review of existing evidence and remaining knowledge gaps. New Haven, CT: Innovations for Poverty Action.

I-FIKR,(2018). Islamic finance body IFSB to develop financial inclusion guidance. https://bit.ly/3dm5JwK

Isaac, J.(2014). 'Expanding Women's Access to Financial Services” February 26, 2014. The world bank. https://bit.ly/3hf8r9H

Islam, M. S. (2014). Microcredit, financial inclusion and women empowerment Nexus in Bangladesh. Stud, 3(2). 6-15.

Jouti, A. T. (2018). Islamic finance: financial inclusion or migration?. ISRA International Journal of Islamic Finance, 277-88. https://doi.org/10.1108/IJIF-072018-0074

Kabeer, N. (2012). Women's economic empowerment and inclusive growth: labour markets and enterprise development. International Development Research Centre, 44(10), 1-70.

Malterud, K., Siersma, V. D., \& Guassora, A. D. (2015). Sample size in qualitative interview studies: guided by information power. Qualitative health research, 26(13), 1753-1760. https://doi.org/10.1177/1049732315617444

Mero-Jaffe, I. (2011). Is that what I said? 'Interview transcript approval by participants: an aspect of ethics in qualitative research. International journal of qualitative methods, 10(3), 231-247. https://doi.org/10.1177/160940691101000304

Miles, M. B., \& Huberman, A. M. (1994). Qualitative data analysis: An expanded sourcebook. Edition 3. Sage.

Muhammad, S., Bhatti, M. N., \& Awan, M. W. (2019). Money, Politics and Gender Equality: An Analysis of Assets of Women Legislators in Pakistan (200213). Global Regional Review, 4(1), 292-302. https://doi.org/10.31703/grr.2019(IVI). 31

Nascimento, L. D. S., \& Steinbruch, F. K. (2019). The interviews were transcribed, but how? Reflections on management research. RAUSP Management Journal, 54(4), 
413-429. https://doi.org/10.1108/RAUSP-05-2019-0092

Onwuegbuzie, A. J., \& Collins, K. M. (2007). A typology of mixed methods sampling designs in social science research. Qualitative Report, 12(2), 281-316.

Qu, S. Q., \& Dumay, J. (2011). The qualitative research interview. Qualitative research in accounting \& management. 8(3), 238-264. https://doi.org/10.1108/11766091111162070

Sayed, M. N., \& Shusha, A. (2019). Determinants of Financial Inclusion in Egypt. Asian Economic and Financial Review, 9(12), 1383-1404. https://doi.org/10.18488/journal.aefr.2019.912.1383.1404

Subramanian, R. (2014). Financial Inclusion-Micro Finance a Sustainable Model. International Journal of Research, 1(6), 566-574.

The Global Findex Database, (2017). Measuring Financial Inclusion and the Fintech Revolution. Washington, DC: World Bank. doi:10.1596/978-1-4648-1259-0. License: Creative Commons Attribution CC BY 3.0 IGO.

Ulfi, I. (2018). Empowering Women through Islamic Microfinance: Experience of BMT Beringharjo. Jurnal Ekonomi dan Bisnis Islam, 3(1), 89-101. https://doi.org/10.15548/jebi.v3i1.147

UNHLP, (2016). Leave no one behind: a call to action for gender equality and women's economic empowerment. Report of the UN- secretary-general's high-level panel on women's economicempowerment. https://www.unscn.org/uploads/web/news/U NSG-HLP-WEE-2nd-Report-.pdf.

United Nations, (2014). Impact of Access to Financial Services, Including by Highlighting Remittances on Development: Economic Empowerment of Women and Youth'. In United Nations Conference on Trade and Development, United Nations, Geneva.

United Nations. (1995), Beijing declaration, Beijing.

United Nations. (2018), Strategies for advancing women's economic empowerment in the context of the Sustainable Development Goals. Economic and Social Commission for Asia and the Pacific. Committee on Social Development. Bangkok. ESCAP/CSD/2018/1. 